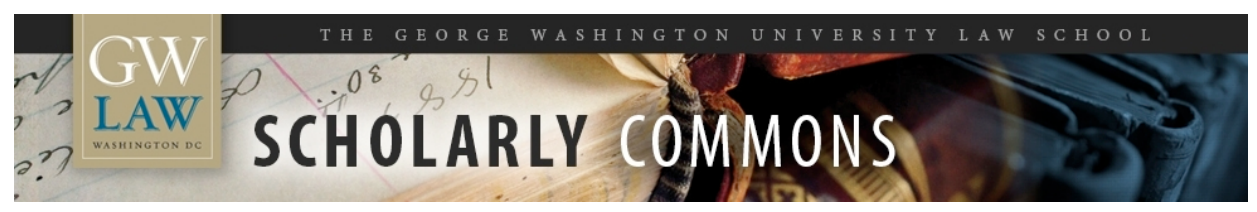

\title{
Food and Condiments For the Twenty-First Century: Business, Science, and Policy
}

Lewis D. Solomon

George Washington University Law School

Follow this and additional works at: https://scholarship.law.gwu.edu/faculty_publications

Part of the Law Commons

\section{Recommended Citation}

Solomon, Lewis D., Food and Condiments For the Twenty-First Century: Business, Science, and Policy (2015). Food and Condiments For the Twenty-First Century: Business, Science, and Policy (1st ed. 2015). ; GWU Law School Public Law Research Paper No. 2015-23; GWU Legal Studies Research Paper No. 2015-23. Available at SSRN: http://ssrn.com/abstract=2630327

This Book Part is brought to you for free and open access by the Faculty Scholarship at Scholarly Commons. It has been accepted for inclusion in GW Law Faculty Publications \& Other Works by an authorized administrator of Scholarly Commons. For more information, please contact spagel@law.gwu.edu. 


\title{
Food and Condiments For the Twenty-First Century: Business, Science, and Policy
}

\author{
Lewis D. Solomon
}


Copyright (C) 2015-Lewis D. Solomon 


\section{Dedication}

For Janet, the love of my life 
Table of Contents

Introduction

I. Replacing a Key Condiment 8

1. Salt and Its Substitutes: Nu-tek Food Science 8

II. Substituting Animal Products: Cheese, Eggs, and Meat 26

2. Factors Driving The Development and

Commercialization of Substitute Animal Products 26

3. Plant-Based Cheese Substitutes: Lyrical Foods 56

4. Plant-Based Egg Substitutes: Hampton Creek 65

5. Plant-Based Chicken and Beef Substitutes: 85

Beyond Meat

6. Plant-Based Beef Substitutes: Impossible Foods 102

7. Bioengineered Meat and Leather: Modern Meadow 106

III. Replacing Conventional and Substitute Foods 128

8. All-In-One Liquid Meal Replacement: Rosa Labs 128

9. Conclusion 146 


\section{Introduction}

We are in the midst of a paradigm shift impacting the food industry. Taking a proactive wellness stance, consumers increasingly focus on the nutrition in the foods they consume. People, especially the millenials, more closely examine the impact of food not only on their health and wellness but also on the environment. Some are also concerned about the relationship between food and animal welfare as well as resource scarcities.

The for-profit companies profiled in this book are leading the reinvention of condiments and food. Sustainable, profitable, scalable firms that create better products will gain market share and ultimately win out, at least among more discerning consumers.

Riding the link between salt and high blood pressure, heart disease, and stroke, as espoused by the public health officials, the first part of this book, Chapter 1, examines Nu-tek Food Science, which sells a salt substitute. Using a patented process, its products reduce sodium chloride content by up to 75 percent, yet deliver the same taste as traditional salt. 
The second part of the book, Chapter 2, begins by critically examining the animal welfare, human health and wellness, resource scarcities, and environmental impact factors on which firms profiled in this part base their products. With perception sometimes trumping the reality with respect to certain of these factors, a ready market exists for animal product substitutes, among some consumers. Chapters 3 to 7 analyze five startup firms that display culinary entrepreneurship combining environmental and vegan ethics, an interest in human health and wellness, a commitment to taste and texture, and a belief that technology and money can improve the world. Each wants to revolutionize what we eat.

These five companies, Lyrical Foods (Chapter 3), Hampton Creek (Chapter 4), Beyond Meat (Chapter 5), Impossible Foods (Chapter 6), and Modern Meadow (Chapter 7) seek to disrupt the annual global trillion dollar animal agricultural industry. Each wants to create healthier and more sustainable products amid concerns about climate change and resource constraints.

Based on the use of various transformative technologies, each of these firms offers a new era for the 
animal products most of us currently eat. The five companies want to give consumers the tastes, textures, looks, and aromas together with the nutritional benefits of foods coming from animals but without the negative human health and environmental aspects.

Four of the firms currently engineer plant-based products that replicate cheeses (Lyrical Foods), eggs (Hampton Creek), and meat (Beyond Meat and Impossible Foods). While initially focused on leather, Modern Meat ultimately looks to develop lab-grown meat, synthesized from animal stem cells.

Although picking winners and also-rans represents a difficult endeavor, some of these startups will emerge to challenge traditional food conglomerates that are not as nimble. Although Kellogg owns the vegetarian food giant Morningstar Farms, the largest veggie food producer in the United States, and Kraft has its Boca Foods brand, each of these five companies wants to out-innovate established food firms. In so doing, they open a new era for alternative animal products, indistinguishable for the real thing, but healthier, more sustainable amid mounting environmental 
concerns and resource constraints, and hopefully as or less expensive.

The third part, Chapter 8, considers the most revolutionary of the efforts - an all-in-one product Soylent, sold by Rose Labs. It would replace grocery shopping and cooking with a liquid meal. The chapter critically considers the benefits and drawbacks of this relatively inexpensive, but efficient food substitute.

As scientists and entrepreneurs seek to remake our relationship with animals and the planet, policy issues run throughout parts two and three of this book. Specific policy issues include the U.S. Food and Drug Administration's standards for products, such as mayonnaise (Chapter 4), as well as the federal government's regulation of cultured meat (Chapter 7) and dietary supplements (Chapter 8). More generally, a federal regulatory framework must evolve to meet how people are now starting to eat substitute animal products. The possible consolidation of the food safety inspection system into one federal agency is discussed in Chapter 9. Beyond scientists, entrepreneurs, and government regulators, funders evidence an interest in these non- 
traditional food startups. With products that help solve big problems - health, environment, food safety, animal welfare, and resource scarcities - and transform the food industry, venture capital firms have gotten involved as funders. These investors in high profile tech startups do not think small; they want to change the world. A group of major venture capital firms, including Khosla Ventures, Kleiner Perkins Canfield \& Byers, and Andreessen Horowitz, as discussed in Chapters 1, 3 through 8, have made a variety of big bets on food and condiments. ${ }^{1}$ Bill Gates ${ }^{2}$ and PayPal co-founder and venture capitalist Peter Thiel's Breakout Labs and Founders Fund are also in the game. Investments by venture capital firms and technology pioneers have given the alternative food industry a tremendous shot of credibility.

Along with scientists and entrepreneurs, these venture capitalists, both firms and individuals, want to transform the food industry and its current, broken impact on human health, the environment, and animals. Fixing it requires innovation and the redesign of systems and processes. For some, food-related startups fit along with other health and wellness investments. Because they seek to lessen the 
adverse environmental impact of producing animal products, others see their investments fitting into their sustainability portfolios, along with solar energy. These venture capitalists do not see innovations emerging from major food conglomerates; rather, they look to startups pioneering innovations. They want to fund something small, see it iterate rapidly, sometimes even having programmers writing code to test plant species, and scale it up. In short, these food startups may behave similarly to the most successful tech companies. ${ }^{3}$

Tackling real world problems and transforming the food industry represents an audacious challenge. As Amol Deshpande, a partner in Kleiner Perkins who specializes in agricultural technology, stated, "Being able to change the game in terms of how we deliver protein to the growing population is probably the biggest thing anybody could do. ${ }^{\prime \prime 4}$

Chapter 9 provides a brief conclusion noting that in the future we may see both plant-based animal products alongside more humanely and sustainably raised animals and less-meat intensive diets. 
${ }^{1}$ See, e.g., Ilan Brat and Jacob Bunge, "Silicon Valley Sows Seeds For New Era In Farm Tech,'" Wall street Journal, April 7, 2015, A1 and Jenna Wortham and Claire Cain Miller, “In Silicon Valley's Kitchen," New York Times, April 29, 2013, B1.

2 Bill Gates, "'Food Is Ripe for Innovation,"' March 21, $2013<W W$. mashable.com/2013/03/21/bill-gates-future-offood> singled out Beyond Meat, Hampton Creek, and Lyrical Foods as "doing some amazing things."

${ }^{3}$ Nick Bilton, “Disruptions: Silicon Valley Makes Its Next Stop the Kitchen,"' New York Times, October 21, 2013, B6. ${ }^{4}$ Amol Deshpande quoted in Ariel Schwartz, "Biz Stone Explains Why Twitter's Co-Founders Are Betting Big On A Vegan Meat Startup,"' Fast Company, June 13, 2012 <wWW. fastcoexist .com/1680007/biz-stone-explains - whytwitters-co-founders-are-betting-big-on-a-vegan-meatstartup> 
I. Replacing a Key Condiment

1. Salt and Its Substitutes: Nu-Tek Food Science Salt saturates our food supply, particularly processed foods including deli meats, canned goods, such as soup, and pizza. This chapter summarizes the studies dealing with the impact of salt consumption on long-term health. Although the impact remains controversial, Nu-Tek Food Science offers two products to meet the demand for reduced salt--sodium chloride--by the food industry, restaurant owners, and the public.

Health Reasons to Reduce Salt Intake

For decades, medical experts have advocated that humans reduce their salt--sodium chloride--intake. They have told individuals, especially those suffering from high blood pressure, those 50 years of age or older, AfricanAmericans, and those who have diabetes or chronic kidney disease, to reduce their salt consumption to lower their blood pressure. Public health officials have long presented the link between salt and heart disease as an established fact. 
The problem is sodium, one of the chemical elements in salt. However, not all sodium is bad. Some sodium is essential to good human health. Sodium helps maintain the correct balance of bodily fluids and transmit nerve impulses as well as influence muscle contraction and relaxation. ${ }^{1}$

A much-cited study carried out by the National Institutes of Health, the DASH (Dietary Approaches to Stop Hypertension)-sodium study, ${ }^{2}$ found that participants put on lower sodium intake diet than the control group, in conjunction with the DASH diet, ended up with significantly lower blood pressure, with a greater impact of the diet and lower sodium consumption in combination than each singly. This study led to public health pronouncements demonizing salt. For example, 2010 Dietary Guidelines for Americans, jointly issued by the U.S. Department of Agriculture and the U.S. Department of Health and Human Services, put salt at the top of the list of things to avoid based on "[a] strong body of evidence in adults that documents as sodium intake decreases, so does blood pressure. ${ }^{\prime 3}$

The reason to avoid salt: The more salt we eat, the more water our body retains, and the more our blood volume 
increases. Water retention makes our hearts work harder, increases our blood pressure until our kidneys flush out the water and the salt. Thus, anti-salt proponents believe that salt has long lasting impact on blood pressure. The ingestion of too much salt over a long time period will result in hypertension and possibly premature death resulting from heart disease, stroke, and kidney failure. Conversely, lowering salt intake would reduce blood pressure, which, in turn, would automatically lower the risk of heart and blood vessel diseases. In short, this hypothesis leads to the conclusion that lower salt intake in the general population, particularly among those who are sodium sensitive, would be beneficial.

Unsuccessful Salt Substitutes

Salt substitutes are not new. Products, such as NuSalt, AlsoSalt, and NoSalt, have been on the market for years. Salt replacement manufacturers removed sodium chloride from their products, replacing (or mixing) it with small amounts of potassium chloride to achieve a blood pressure lowering impact. ${ }^{4}$ They used expensive flavor enhancers to mask the unpleasant, often bitter metallic 
taste of the substitute minerals, which otherwise would ruin a product's taste. ${ }^{5}$ Processed food producers typically try to mix a potassium chloride salt substitute with other ingredients. Because the different flavor components hit the tongue at different times, eaters usually pick up the metallic taste. Other firms try pressing all the materials together, but they come apart in food processing and the metallic taste appears again. Swapping potassium chloride for sodium chloride also throws other ingredients, such as sugar and fat, in processed foods out of whack. With the strength of these other ingredients diminished, processors add more sugar and fat, to maintain, if not enhance, their products' allure. ${ }^{6}$

Nu-Tek Food Science

Nu-Tek Food Science, LLC (Nu-Tek), founded in 2006, offers potassium chloride products to meet the demand for reduced sodium chloride in the food industry, as well as by restaurant operators, and the general public. The firm has as its mission "to help create great-tasting and 
affordable food that enhances global health and wellness, ${ }^{\prime 7}$ and at the same time maintaining "great taste, affordability, and ease of use. ${ }^{\prime \prime 8}$

At present, Nu-Tek offers two products, NuTek Salt and Salt for Life. ${ }^{9}$ NuTek Salt is a product for food manufacturers and restaurant chains. According to Nu-Tek, some 10 of the top 13 global food producers have started incorporating the product. Salt for Life, which blends potassium salt, using its NuTek Salt process, with sea salt, targets health-conscious consumers.

Nu-Tek replaces a significant amount of sodium chloride in its NuTek Salt with a proprietary, unified crystal fashioned from potassium chloride and an organic acid, thereby achieving flavor uniformity. More specifically, Nu-Tek takes potassium chloride and sodium chloride, turns them into a wet slurry to dilute the mixture, blends the mixture with an organic acid, and recrystallizes it. Because the materials are no longer separated, but are bound together in a single crystal, "You don't get that traditional bitter metallic note, and you can use [the salt replacement] at much higher levels. ${ }^{\prime \prime 10}$ 
Initially, Nu-Tek sold its product to food processors that were getting serious about lessening the sodium chloride in their meat, poultry, cheese, bakery, spice blends, soups, sauces, and gravies. Nu-Tek's formula enabled these companies to reduce their products' sodium content by 30-50 percent and often in excess of 50 percent. ${ }^{11}$ Thus, in meeting consumers' needs for low-sodium chloride products, food processors could offer consumers healthier products without changing their taste or functionality, at a minimal cost.

As the next step, the company rolled out its consumer friendly product to restaurant operators and then to the general public. Its Salt for Life can be used in the same way and in the same amounts as sodium chloride salt to season, cook, or bake. This salt replacement product, with 75 percent less sodium than common salt, ${ }^{12}$ is available in a tabletop shaker, a retail-sized canister, and individual sachets. Consumers could obtain NuTek's Salt for Life initially on Amazon.com and beginning in 2013 in selected U.S. supermarkets. In 2015, it relaunched the brand, with a refreshed packaging design and a revamped logo. ${ }^{13}$ 
In addition to those who suffer from high blood pressure, in the future, Nu-Tek's consumer product may appeal to a more general public market. It will likely represent an option for people who have grown accustomed to ever higher amounts of salt in their diet, especially large amounts of salt in processed items.

Financing $\mathrm{Nu}-\mathrm{Tek}$

In February 2012, Khosla Ventures LLC, a leading information and green technologies venture capital firm, made a significant, but undisclosed, equity investment in Nu-Tek. The company used the funds to increase its infrastructure and overall capacity and to accommodate growing client demand and market needs for a reduction in sodium levels. Thomas L. (Tom) Manuel, Nu-Tek's Chief Executive Officer, noted, "This great partnership with Khosla Ventures will allow us to expand our capacity for our current customers and take advantage of the growing sodium-reduction market. With our improved potassium chloride technology, we are able to provide unmatched lower-sodium alternatives to our customers in a cost- 
effective manner while maintaining the taste, flavor and functionality historically seen in processed foods. ${ }^{14}$

\section{Award Received}

In 2013, the National Restaurant Association presented Nu-Tek's Salt for Life Sea Salt Blend with one of its 2013 Food \& Beverage Innovations Awards (FABI Award). ${ }^{15}$ The FABI Award recognized innovative consumable products delivering significant benefits to restaurant operators and the food industry. An independent panel of industry leaders, representing a variety of commercial and noncommercial food industry segments, selected the Salt for Life product for the award.

The Science Reconsidered

The DASH study represents one of the many that have examined the impact of salt intake on health. However, salt's consumption on long-term health remains controversial. Two meta-analyzes, which summarize the results from many empirical studies, have raised doubts about the previous consensus of medical opinion.

Although finding that reducing salt intake leads to lower systolic blood pressure, one meta-analysis concluded 
that "no strong evidence" exists that this will result in fewer premature deaths or a lower incidence of heart disease. ${ }^{16}$ Another meta-analysis concluded that "we do not know if low salt diets improve or worsen health outcomes. ${ }^{\prime \prime 17}$

Other researchers go one step further than the second meta-analysis. They maintain that reducing salt intake increases one's risk of dying. The reason: the body needs a fair amount of sodium chloride daily. If a person gets too little sodium chloride, the kidneys secrete an enzyme, renin, which may have harmful effects on blood vessels and may lead to hypertension and cardiovascular disease.

Some studies have even found that low sodium intake was associated with an increase risk of heart failure. One recent study, what has become known as The Best Evidence Study, ${ }^{18}$ found that only the systolic (the top) blood pressure level slowly rises over time with increased salt intake. However, this rise did not translate into a higher risk for high blood pressure or heart and blood vessel disease. The study concluded:

The associations between systolic pressure [the top blood pressure number] and sodium excretion did not translate into less morbidity or improved survival. On the contrary, low sodium excretion 
predicted higher cardiovascular [heart and blood vessel disease] mortality. Taken together, our current findings refute estimates of computer models of lives saved and health care costs reduced with lower salt intake. They also do not support the current recommendations of a generalized and indiscriminate reduction of salt intake at the [general] population level. However, they do not negate the blood-pressure lowering effects of a salt reduction in hypertensive patients. ${ }^{19}$

Two reasons may account for the death rates getting progressively worse in this study as salt intake decreased. First, low salt intake can lead to a loss of insulin sensitivity. As the definition of type 2 diabetes, this loss may represent a major factor in blood vessel inflammation, arteriosclerosis, and heart disease. Second, low salt intake can lead to insufficient production of digestive enzymes, which lead to the poor absorption of vitamins and minerals, possibly leading, in turn, to heart and blood vessel disease. ${ }^{20}$

Others suggest that the key to heart health may rest on a low sodium-to-potassium ratio. The more potassium we consume, the more sodium is excreted through urine out of the body. Potassium also helps relax blood vessel walls, thereby lowering blood pressure. Too little potassium, in their view, is associated with cardiovascular problems. 
Thus, a need exists for a therapeutic salt, such as $\mathrm{Nu}$ Tek's products, with decreased sodium and increased potassium. However, too large amounts of potassium are linked to kidney problems, notably kidneys less able to remove potassium from the blood, especially for those taking medications for congestive heart failure or high blood pressure which often cause potassium retention. ${ }^{21}$ Despite the focus in this chapter on sodium and potassium, these elements are only some of the dietary factors that may affect blood pressure. Other factors include the type and amount of dietary fat, as well as levels of cholesterol, protein, fiber, calcium, and magnesium.

${ }^{1}$ Mayo Clinic, Healthy Lifestyle: Nutrition and healthy eating, August 19, 2014 <wWw.mayoclinic.org/healthliving/nutrition-and-health-eating/in-depth/sodium/art$20045479>$.

${ }^{2}$ Frank M. Sacks et al., "Effects on Blood Pressure of Reduced Dietary Sodium And Dietary Approaches To Stop Hypertension (DASH) Diet,'" New England Journal of Medicine 344:1 (January 4, 2001):3-10. See also Paul $\mathrm{K}$. Whelton et al., "Sodium, Blood Pressure, and Cardiovascular Disease: 
Further Evidence Supporting the American Heart Association in Sodium Reduction Recommendations, '" Circulation 126:7 (December 11, 2012):2880-2889, "'Erratum," Circulation 127:1 (January 1, 2013):e263 and Francis Dumler, “Dietary Sodium Intake and Arterial Blood Pressure,"' Journal of Renal Nutrition 19:1 (January 2009): 57-60. Meta-analyses include Dariush Mozaffarian, "Global Sodium Consumption and Death from Cardiovascular Causes," New England Journal of Medicine 371:1 (August 14, 2014):624-634 (meta-analysis of 107 global randomized interventions); Nancy J. Aburto et al., "Effect of lower sodium intake on health: systematic review and meta-analyses," British Medical Journal 346:f1325 doi:10.1136/bmj.f1325 (April 5, 2013) (14 cohort studies and 42 randomized controlled trials); Feng J. He, Jiafu Li, Graham A. Macgregor, "Effect of longer term modest salt reduction on blood pressure: Cochrane systematic review and meta-analysis of randomised trials," British Medical Journal 346:f1325 doi:10.1136bmj.f1325 (April 5, 2013) (meta-analysis of 34 randomized controlled trials); Pasquale Strazzulo et al., "Salt intake, stroke, and cardiovascular disease: meta-analysis of prospective 
studies,'" British Medical Journal 339:7733 (December 5, $2009): 1296$.

${ }^{3}$ U.S. Department of Agriculture and U.S. Department of Health and Human Services, Dietary Guidelines for Americans $20107^{\text {th }}$ ed., December 2010, 21 and Dietary Guidelines Advisory Committee, Report of the Dietary Guidelines Advisory Committee on the Dietary Guidelines for Americans, 2010, To the Secretary of Agriculture and the secretary of Health and Human Services, May 2010, 4-5, 16, 327-336. Continuing to link sodium intake and blood pressure, the 2015 Dietary Guidelines Advisory Committee stated: “In excess, sodium is associated with several adverse health events, particularly hypertension."' Scientific Report of the 2015 Dietary Guidelines Advisory Committee, Advisory Report to the Secretary of Health and Human Services and the Secretary of Agriculture, February 2015, Part D. Chapter 6, 11. The report summarized the scientific evidence for its conclusion at Ibid., Part D. Chapter 6, 311. See also Robert H. Eckel et al., “2013 AHA/ACC Guideline on Lifestyle Management to Reduce Cardiovascular Risk: A Report of the American College of Cardiology/American Heart Association Task Force on 
Practice Guidelines," Circulation 63:25:Part B (July 2014):2960-2984, at 2972 ("There is strong and consistent clinical trial evidence that reducing sodium intake lowers [blood pressure]."') But see Institute of Medicine (IOM), Sodium Intake In Populations: Assessment of Evidence (Washington, DC: National Academies Press, 2013), 122 concluding that the reviewed evidence "indicates a positive relationship between higher levels of sodium intake and CVD [cardiovascular disease]. This evidence is consistent with existing evidence on blood pressure as a surrogate indicator of CVD risk.'" However, no rationale exists for anyone to aim for sodium levels below 2,300 milligrams a day. See also Gina Kolata, "No Benefit Seen in Sharp Limits on Salt in Diet,"' New York Times, May 15, 2013, A1. For background on the contentious debate over dietary salt see Peter Whoriskey, "Experts can't agree on how much salt is too much,"' Washington Post, April 7, 2015, A1; Elliott Antman, "Yes: Less Salt Reduces the Risk of Heart Disease,"' Wall Street Journal, March 23, 2015, B1; David A. McCarron, "No: A Low-Salt Diet Is Neither Safe Nor Feasible,"' Wall street Journal, March 23, 2015, B1. 
${ }^{4}$ IOM, Dietary Reference Intakes For Water, Potassium, Sodium, Chloride, and Sulfate: Panel on Dietary Reference Intakes for Electrolytes and Water: Standing Committee on the Scientific Evaluation of Dietary Reference Intakes: Food and Nutrition Board (Dietary Reference) (Washington, DC: National Academies Press, 2005), 186-187, 197-219. See also Feng J. He et al., "Effect of Short-Term Supplementation of Potassium Chloride and Potassium Citrate on Blood Pressure in Hypertensives, '" Hypertension 45:4 (April 2005):571-574.

${ }^{5}$ See, e.g., Dominique A. Sinopoli and Harry T. Lawless, "Taste Properties of Potassium Chloride Alone and in Mixtures with Sodium Chloride Using a Check-All-That-Apply Method,'" Journal of Food Science 77:9 (September 2012):S319-S322. See also Jonathan Fahey, "The Fake Salt Problem,"'Forbes.com, September 23, 2009 <wWW forbes.com/2009/09/22/taste-buds-science-technologysalt.html>.

${ }^{6}$ Michael Moss, Salt Sugar Fat: How the Food Giants Hooked Us (New York: Random House, 2013), 294.

7 Nu-Tek Food Science (Nu-Tek), "About Us: On a Mission" $<w W w$. nuteksalt.com/aboutus> (September 11, 2014). 
${ }^{8} \mathrm{Nu}-\mathrm{Tek}$, "FAQ's Company"' <WWW. nuteksalt.com/faq> (November 7, 2014).

${ }^{9}$ For background on Nu-Tek see Ariel Schwartz, “'TasteTesting An Incredibly Realistic Salt Replacement (That You've Been Eating All Along),'" Fast Company, July 25, $2013<w W W$. nuteksalt. com/documents/FastCompany-TasteTesting-An-Incredibly-Realistic-Salt-Replacement.pdf> and Michael Kanellos, "Salt: A Favorite Ingredient Gets A Molecular Makeover,'" Forbes.com, September 5, 2012 <WWW. forbes.com/sites/michaelkanellos/2012/09/05/salt -a favorite-ingredient-gets-a-molecular-makeover>. ${ }^{10}$ Donald (Don) Mower, Nu-Tek's then President and Chief Operating Officer quoted in Schwartz, "Taste-Testing." $\mathrm{Nu}-\mathrm{Tek}^{\prime} \mathrm{s}$ reduced sodium products incorporate a patented technology. Francis Raymond Salemme, Abraham I. Bakal, Richard Bamdt, Compositions and Methods for producing flavored seasonings that contain reduced quantities of common salt, US 7452563 B2, November 18, 2008. The patent was assigned to Nu-Tek on April 26, 2013. For a summary of the firm's patent position see Nu-Tek, Press Release, "NuTek Food Science Achieves Unprecedented Levels of 
Sodium Reduction With The Support of Its Significant Patent Portfolio,"' October 30, 2014.

${ }^{11} \mathrm{Nu}-\mathrm{Tek}$, "FAQ's Products" <WWW. nuteksalt.com/faq> (November 7, 2014).

12 Ibid.

${ }^{13} \mathrm{Nu}$-Tek, Press Release, "'Salt for Life Shakes Up Culinary Category with Brand Re-Launch,"' February 26, 2015.

${ }^{14} \mathrm{Nu}$-Tek Salt, Press Release, “Nu-Tek Salt, LLC To Expand Capacity With Khosla Ventures Partnership,"' February 28, 2012. See also Food Weekly News, "Nu-Tek Salt, LLC to Expand Capacity with Khosla Ventures,'" March 15, 2012,

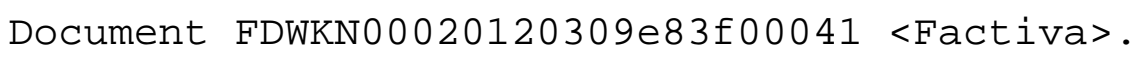

15 Nu-Tek, Press Release, "Salt for Life ${ }^{\text {TM }}$ Sea Salt Blend from Nu-Tek Food Science Receives 2013 FABI Award,"' April $30,2013$.

${ }^{16}$ Rod S. Taylor et al., "Reduced Dietary Salt for the Prevention of Cardiovascular Disease: A Meta-Analysis of Randomized Controlled Trials (Cochrane Review),"' American Journal of Hypertension 24:8 (August 2011):843-853, at 851. 17 Niels Albert Graudal, Thorbjorn Hubeck-Graudal, Gesche Jurgens, "Effects of low sodium diet versus high sodium diet on blood pressure, renin, aldosterone, catecholamines, 
cholesterol, and triglyceride (Review),"' Cochrane Database of Systemic Review 2011, issue 11, Article No.: CD@๑4022. DOI: $10.1002 / 14651858 . C D \odot \odot 4 \odot 22$. pub3.

${ }^{18}$ Katarzyna Stolarz-Skrzypek et al., "Fatal and Non-fatal Outcomes, Incidence of Hypertension, and Blood Pressure Changes in Relation to Urinary Sodium Excretion,"' Journal of the American Medical Association 305:17 (May 4, 2011):1777-1785. However, too much or too little sodium intake may be equally problematic for some people. A metaanalysis investigated the association between sodium chloride intake and adverse health outcomes, such as cardiovascular disease and all-cause mortality. Researchers analyzed 23 cohort studies and two follow up studies, generating a sample size of nearly 275,000 $(274,683)$ people. The study concluded that both low sodium intakes and high sodium intakes are associated with increased mortality, consistent with a U-shaped association between sodium intake and health outcomes. Niels Graudal et al., "Compared With Usual Sodium Intake, Low-and Excessive-Sodium Diets Are Associated With Increased Mortality: A Meta-Analysis," American Journal of Hypertension 27:9 (September 2014):1129-1137, at 1129. See 
also Andrew Mente et al., "Association of Urinary Sodium and Potassium Excretion with Blood Pressure, "' New England Journal of Medicine 371:7(August 14, 2014):601-611 and Martin 0'Donnell et al., "Urinary Sodium and Potassium Excretion, Mortality, and Cardiovascular Events," New England Journal of Medicine 371:1 (August 14, 2014):612623. For an overview of salt's health impact by an independent investigator on health policy research see Gary Taubes, "Salt, We Misjudged You," New York Times, June 3, 2012, SR8. See also Melinda Wenner Moyer, "It's Time to End the war on Salt: The zealous drive by politicians to limit our salt intake has little basis in science, '" Scientific American, July 8, 2011

$<W W$. scientificamerican.com/articles/its-time-to-end-thewar-on-salt>.

19 Stolarz-Skrzypek, "Fatal and Nonfatal Outcomes," 1784.

${ }^{20}$ Health Alert, "Low-Salt "Experts"' Cringing," 28:9 (September 2011): 1-2, at 2 .

${ }^{21}$ IOM, Dietary Reference, 187-188, 241-242, 249. 
II. Substituting Animal Products: Cheese, Eggs, and Meat 2. Factors Driving the Development and Commercialization of Substitute Animal Products

This chapter surveys the four factors driving businesses to limit the damage from eating animal meat or animal by-products, such as milk and eggs, on our lives and on the planet: animal welfare; human health and wellbeing; resource constraints; and environmental impacts. ${ }^{1}$ The chapter briefly analyzes the validity of each of these factors and assesses whether the traditional animal products have often alleged adverse impacts on our lives and on the planet.

Animal Welfare

Proponents of animal substitutes focus on animal welfare, specifically, treating animals as if they mattered, thereby reducing their suffering. ${ }^{2}$ Building on the new morality that humans should not exploit animals for our own benefit, they also seek to heighten our guilt resulting from the consumption of sentient nonhuman beings who have intrinsic moral value. 
Today, in factory-like farms and industrial feedlots, billions of chickens and cows spend their lives in inhumane, deplorable conditions. They are crammed into cages or pens. Packed in, body-to-body, even in enriched cages, so tightly that chickens cannot spread their wings. They are raised in their own waste, fed growth-enhancing chemicals, and eat antibiotic-laden soy and corn to help them grow until their slaughter. Egg-production systems involve killing unwanted one to three day-old male chickens. Male calves useless in the milk production industry are either killed shortly after birth or sent for veal production after castration and dehorning.

Even if animals are treated with compassion and attention to their well-being, being raised cage-free, with enhanced outdoor exercise, without growth hormones or antibiotics, chickens still face a frightening death with their flesh becoming food. Also, layer hens and dairy cows, among other animals, face elimination when their bodies are spent, their production drops, and they become burdensome. Thus, plant-based foods, including cheese, eggs, and meat, as well as lab-grown meat are viewed as the 
way technology can help animals; especially as more meat lovers react to the horrors of confinement raising. However, looking to plant-based substitutes would still result in the killing of animals of the field, such as rodents. Although accurate mortality numbers are unavailable, human actions by tractors and other farm implements run over animals. Plows and cultivators destroy their underground burrows and kill them. By removing ground cover, harvesting crops allows predators to kill small mammals on the surface. ${ }^{3}$ The application of pesticides, another type of human action, also kills animals of the field.

Human Health and Wellness

Plant-based cheese, eggs, and meat and lab-grown beef would promote human health and wellness in two ways: increasing food safety and improving human health.

Food Safety Concerns

Known foodborne pathogens, such as E. coli and salmonella, are responsible for some 9 (9.4) million illnesses, nearly 56,000 (55,961) hospitalizations, and 
more than $1,300(1,351)$ deaths each year in the United States alone. Unspecified foodborne agents account for an additional 38 (38.4) million illnesses, nearly 72,000 $(71,878)$ hospitalizations and $3,000(3,037)$ deaths annually in the United States. ${ }^{4}$ Nearly every test of supermarket chicken, for example, finds high percentages, sometimes reaching two out of every three samples, of staph, salmonella, or disease-causing antibiotic-resistant bacteria. ${ }^{5}$ By eating meat, especially where animals in close contact breed disease, humans are exposed to many virus-causing diseases, such as avian influenza.

The rampant use of antibiotics in the production of cows and chickens, among other animals, not only makes these drugs less effective but also encourages the development of hardier disease-causing bacteria. Every time animals receive antibiotics a chance exists that bacteria develop resistance to it. Resistant bacteria pass from animals to humans, primarily in the food chain. When animals are slaughtered and processed, bacteria in the meat can be carried into consumers' kitchens. ${ }^{6}$

Public Health Concerns 
Public health concerns arise from eating animal

products. There are two alleged culprits: cholesterol and fats, which raise the risk of myriad ailments, including heart disease, strokes, diabetes, and some cancers, at least we are told. In particular, some research points to the unhealthy consequences of red meat consumption. According to one study, after controlling for various variables, three additional ounces of unprocessed red meat a day was associated with a 12 percent greater risk of dying overall, a 16 percent higher risk of cardiovascular death, and a 10 percent greater risk of cancer death. Conversely, if the people in the study $(n=121,342)$ had eaten one half as much meat, researchers estimated that deaths in the group would have declined 9.3 percent for men and 7.6 percent for women. ${ }^{7}$

Cholesterol

Physicians have long maintained that cholesterol, particularly high levels of LDL, the "bad" cholesterol, increases the risk of heart disease and stroke. For example, in 2002, the National Institutes of Health's National Cholesterol Education Program called elevated LDL- 
cholesterol a "powerful risk factor" for cardiovascular disease. $^{8}$ The 2010 Dietary Guidelines for Americans more cautiously noted, “Moderate evidence shows a relationship between higher intake of cholesterol and higher risk of cardiovascular disease. ${ }^{\prime 9}$ Thus, LDL cholesterol represents the biomarker widely used to condemn saturated fat found in animal products.

However, studies have negated LDL-cholesterol as a meaningful predictor of the risk of heart attack, at least for most people. ${ }^{10}$ Cholesterol levels may have little or nothing to do with the amount of plaque in human arteries, the thickening of blood vessels, and the choking off of blood flow to the heart and thus with heart disease. Thus, Americans need not avoid egg yolks, liver, and shellfish, among other foods.

\section{Saturated Fat}

Physicians generally recommend a low-fat diet, keyed to avoiding saturated fat found, for example, in meat. Thus, tightly controlling the percentage and types of fat would improve the health benefits of plant-based or labgrown animal products. These substitutes, particularly 
meat and cheese, can be produced with limited amounts of saturated fat.

Since 1980, the Dietary Guidelines for Americans (Dietary Guidelines) have urged Americans to cut back on fat, particularly the saturated kind found in animal products, such as red meat, milk, cheese, and eggs. ${ }^{11}$ These guidelines recommend replacing these foods with more fruits, vegetables, and grains. By 2010, the Dietary Guidelines backed off from mentioning any specific percentage limits on the total consumption of fat, only noting:

A strong body of evidence indicates that higher levels of most dietary saturated fatty acids is associated with higher levels of blood total cholesterol and low-density lipoprotein (LDL) cholesterol. Higher total and LDL cholesterol levels are risk factors for cardiovascular disease. ${ }^{12}$

However, the 2010 Dietary Guidelines ratcheted the allowable amount of saturated fat down to 7 percent or less of one's daily calories, not the 11 percent daily consumed by adults, so as to "further reduce the risk of cardiovascular disease. ${ }^{\prime 13}$ Although not explicitly stated in the Dietary Guidelines, by inference we should cut back on the amount of red and processed meat as well as cheese 
consumed. The Dietary Guidelines recommend an increased intake of fat-free or low-fat cheese, both of which may taste "awful" and eating meat and poultry in lean forms, which often lack flavor and mouthfeel, to reduce fat consumption. ${ }^{14}$

Despite these guidelines, two massive clinical trials funded by the National Institutes of Health failed to show any benefits of a low saturated fat diet in improving human health. ${ }^{15}$ Two meta-analyses of all available evidence concluded that saturated fat does not cause heart disease. ${ }^{16}$ Conversely, according to another meta-analysis, current empirical evidence does not support cardiovascular guidelines encouraging the low consumption of total saturated fats. ${ }^{17}$

Thus, consuming animal products is not unquestionably bad for us. ${ }^{18}$ Saturated dairy fat, for instance, likely has some positive health benefits. One writer summarized evidence with respect to saturated fat as follows:

The sum of the evidence against saturated fat over the past half-century amounts to this: the early trials condemning saturated fat were unsound; the epidemiological data showed no negative association; saturated fat's effect on LDL-cholesterol (when properly measured in subfractions) is neutral; and a significant body of clinical trials over the past decade has 
demonstrated the absence of any negative effect of saturated fat on heart disease, obesity, or diabetes. In other words, every plank in the case against saturated fat has, upon rigorous examination, crumbled away. ${ }^{19}$

Resource Scarcities

Animal products are seen as using too many resources, including land, water, and energy. Proponents raise the often-asked question: If the global population does not peak soon, how will we feed an estimated 9 billion people in 2050 , up from the present 7.2 billion? ${ }^{20}$

Today, each year, humans worldwide consume about 270 million tons of meat. By 2050 , estimates place meat consumption at nearly 500 (470) million tons per year. ${ }^{21}$ The growth in the world's population, ongoing urbanization, and the rising middle class in China, among other nations, will increase the global demand for meat, eggs, and dairy. Even if it is possible for innovation in livestock management to increase production, so as to meet the growing demand, apart from the impact of climate change, analyzed in the next section, land and water resources will come under greater strain.

Livestock consume large amounts of calories in feed to produce the meat, dairy, and eggs we consume. For every 
100 calories of grain fed to animals, humans obtain about 40 calories of milk, 22 of eggs, 12 of chicken, and 13 of beef. ${ }^{22}$

A considerable portion of the arable land in use today goes to feeding and dealing with livestock. Estimates indicate that livestock production, directly or indirectly, accounts for 30 percent of the earth's usable surface land not covered by water and ice, or is bare rock. ${ }^{23}$

With undrinkable sea water accounting for 97.5 percent of the earth's water and only 2.5 percent is fresh water, with 70 percent of this 2.5 percent trapped in glaciers and permanent snow, ${ }^{24}$ the fresh water situation is most alarming. Today, raising livestock consumes about one quarter (23 percent) of the water's available freshwater. It takes 15,500 liters of water to produce one kilogram of beef. During its lifetime, on average, throughout the globe, a cow eats 1,300 kilograms of grain (wheat, oats, barley, corn) and 7,200 kilograms of roughages (pasture, dry hay). ${ }^{25}$ The production of feed requires the withdrawal of significant amounts of fresh water. The exact amount of water used for feed production depends on a number of factors, including the region, feed composition, and the 
origin of the feed ingredients. Besides water to grow fodder, each cow also needs water for drinking, servicing, and product processing.

In addition to using freshwater, the livestock industry damages the earth's increasingly scarce freshwater resources in other ways, by contributing, among other things, to water pollution. The major polluting agents include animal wastes, antibiotics and hormones, fertilizers, and pesticides used to spray feed crops. The runoff from these polluting agents disrupts rivers, lakes, and groundwater worldwide. Widespread overgrazing of livestock also upsets water cycles thereby decreasing the replenishment of above and below ground fresh water resources. ${ }^{26}$

The bottom line with respect to livestock and the global land and fresh water problems: The planet must manage its food better for a massive number of people. We need to find more efficient ways to make proteins. At present, meat, dairy, and egg industries function as highly inefficient ways to produce proteins. One solution: plantbased animal products which likely produce protein more efficiently, more cheaply, and with less energy. 
Proponents of lab-grown meat, for example, point to this product's ability to conserve resources. In comparison to conventionally produced meat in Europe, estimates indicate that cultured meat could reduce the need for water by 82 to 96 percent and land by 99 percent, depending on the specific product. ${ }^{27}$ However, plant-based products may lack necessary nutrients found in traditional meat and eggs. Businesses must supplement their plant-based substitutes with vitamins, especially the B vitamins, and minerals, such as iron.

\section{Environmental Impact}

Alarmist environmentalists and many climate scientists view nasty future climate effects as our era's defining challenge. Unless significant changes are made with respect to fossil fuels, they foresee a global environmental catastrophe.

The voices of impending doom look to the reports of the United Nations Intergovernmental Panel on Climate Change, a worldwide committee of scientists charged with periodically assessing and summarizing the public scientific literature on the current state of the world's 
climate science. In its latest synthesis report for policymakers, the panel stated that "[w]arming of the climate system is unequivocal... ${ }^{\prime \prime 28}$ As the result of climate change, the "atmosphere and oceans have warmed, the amounts of snow and ice have diminished, and sea levels have risen. ${ }^{\prime \prime 29}$

The human impact on greenhouse gas emissions, specifically, the increase in the concentration of greenhouse gases, represents a key factor in climate change. Among other greenhouse gases, carbon dioxide serves as an essential element for earthly life. It enables green plants to convert sunlight into energy. However, at excessive levels, resulting, in part, from the burning of fossil fuels, particularly coal, as amplified by water vapor, it traps heat from the sun, causing the plant's surface to warm, at least the argument runs. Looking to the future, the IPCC report noted that projected global mean temperature change, in 2081-2100 from the 1986-2005 mean, would likely range between 1.5 and 4.8 degrees Celsius, depending on the level of carbon dioxide emissions and the extent of future mitigation. ${ }^{30}$ Thus, if current trends continue, according to the report, the world 
probably will see major disruptions to natural ecosystems and human civilization, marked by food shortages from the difficulties in growing food, especially in the Southern hemisphere, a rapid rise in sea levels resulting in the flooding of major cities and island nations, precipitation changes, and extreme weather. ${ }^{31}$

Large-scale industrial livestock production adversely impacts the environment. It represents a major contributor, if not one of the greatest contributors, to greenhouse gas production.

Livestock activities worldwide produce in aggregate some twenty (18) percent of the non-natural global greenhouse gas emissions. ${ }^{32}$ Livestock production is responsible for more greenhouse gas emissions than the transportation sector, specifically, all the world's cars, trucks, buses, trains, ships, and planes combined. A considerable amount of fossil fuels are burned in the process of meat production, including the making and transport of feed, the rearing and slaughter of livestock, and the processing and shipment of meat. Cattle, among other ruminants, which eat grass, burp methane into the air as a byproduct of their digestion thereby contributing to 
greenhouse gas emissions. The processing of animal waste, most of which is not recycled into fertilizer, releases methane and nitrous oxide into the atmosphere and also pollutes the groundwater. Methane and nitrous oxide are far more powerful greenhouse gases than carbon dioxide. Methane and nitrous oxide have, respectively, 21 and 296 times the global warming potential of carbon dioxide. ${ }^{33}$ Including the emissions from land use, the global livestock industry accounts for 9 percent of the carbon dioxide derived from non-natural/human-related activities, 35-40 percent of the methane emissions, and 65 percent of nitrous-oxides, ${ }^{34}$ with exact percentages varying by country and continent.

Proponents of plant-based or in vitro animal products see these substitutes as a significant, potential solution to climate change, which, as noted, is said to threaten the planet in the twenty-first century. They look to one study, where researchers estimated that lab-grown meat, in comparison to conventionally produced European meat, could, based on a theoretical, highly optimized model of in vitro meat production, cut overall energy use by 7 to 45 percent 
and lower greenhouse gas emissions by 78 to 96 percent, depending on the type of meat. ${ }^{35}$

Some experts dispute the more catastrophic predictions being made. Viewing it unlikely that we face an environmental disaster, they remain skeptical about the claims being made regarding the causes and effects of climate change. They foresee the warming likely to be limited and its impacts manageable. ${ }^{36}$

Two points are not in dispute. Over the past century or so, the planet has warmed by a small amount, some 0.2 degrees Celsius during the last four decades, and sea levels have risen slightly. Humanity has had a role, albeit small, in these warming and sea level trends. For nearly 150 years, we have burned large amounts of fossil fuels and raised countless billions of livestock, however, with minimal impact on the climate.

Importantly, a slowdown in global warming has occurred over the past two decades or so. Although the IPCC report acknowledged this trend, it noted that "the globally averaged surface temperature exhibits substantial decadal and interannual variability, ${ }^{\prime \prime 37}$ but the causes of the temperature variability are not fully understood. Computer 
models were, however, unable to predict the long and continuing pause in the warming thereby placing in doubt the notion that climate science is settled and the future accuracy of the impact of global climate change.

Looking to the future, complex computer models, for example, those used in studies relied on by the IPCC, have a dismal record in predicting future temperatures and sea levels. They oversimplify the complexity of the earth's climate. It remains difficult to untangle the human impact on climate, including livestock production, from natural temperature variations. In other words, considerable natural, unforced variability exists with respect to climate trends. Also, the earth may be less sensitive to increasing greenhouse gas concentrations and the planet may not heat up as much as the IPCC predicts. Variations in solar radiation may impact on climate. Recently, observation-based studies have found less climate sensitivity as the result of greenhouse gases than those using global computer models. One study estimates that the warming during the next seventy years, if carbon dioxide concentrations double, at a manageable 1.33 degrees Celsius, with a range of 1.05 to 1.80 degrees Celsius. ${ }^{38}$ 
The for-profit businesses profiled in Chapter 3 through 7, offering plant-based and cultured animal product substitutes, strongest arguments focus on animal welfare and food safety. In response, producers have begun to raise animals with more compassion ${ }^{39}$ and eliminate, or at least reduce, the use of antibiotics. ${ }^{40}$ The widely trumpeted health and wellness as well as environmental impacts, which have public relations value, may not be grounded in reality. However, perception may be more important than reality. Public opinion sees climate change as a growing threat--we're going to cook the planet if we don't do something about greenhouse gas emissions. Responding to concerns about negative environmental consequences, traditional meat and dairy industries have sought to mitigate their climate impacts through various techniques, including reusing waste and biogas and increasing the amount of carbon sequestered on farm land. Also, a growing number of people believe that consuming animal products is insidious to human health and wellness. The bottom line: based on one or more of these four factors, animal welfare, human health and wellness, 
resource scarcities, and climate change, for-profit businesses build their futures around plant-based and cultured animal products.

${ }^{1}$ See, e.g., Mark J. Post, "Cultured meat from stem cells: Challenges and prospects," Meat Science 92:3 (November 2012): 297-301, at 297-298.

${ }^{2}$ For a discussion of the various definitions of animal welfare see Giuseppe Bertoni and Luigi Calamari, “Animal Welfare and human needs: are they contradictory?"' in EurSafe 2001: Food Safety, Food Quality and Food Ethics, ed. Matias Pasquali (Milan, Italy: A\&Q, 2001), 24-25. ${ }^{3}$ T.E. Tew and D.W. Macdonald "The Effects of Harvest on Arable Wood Mice,"' Biological Conservation 65:3 (January 1993): 279-283, reported that the wood mouse population density in cereal fields dropped by 80 percent from preharvest to post-harvest. They attributed the decrease to migration from the field and mortality, with an estimated mortality rate of 52 percent. See also Steven L. Davis, "The Least Harm Principle May Require That Humans Consume A Diet Containing Large Herbivores, Not A Vegan Diet,'" Journal of Agricultural and Environmental Ethics 16:4 (July 2003): 387-394, at 389-390. But see Andy Lamey, “Food 
Fight! Davis versus Regan on the Ethics of Eating Beef,'" Journal of Social Philosophy 38:2 (Summer 2007): 331-348, at 332-339 and Gaverick Matheny, "Least Harm: A Defense of Vegetarianism From Steven Davis's Omnivorous Proposal,'" Journal of Agricultural and Environmental Ethics 16:5 (September 2003): 505-511, at 506-507.

${ }^{4}$ Renée Johnson, Food Safety Issues for the $114^{\text {th }}$ Congress, Congressional Research Service, R42885, February 13, 2015, 5-6, at 5 (Table 1. Number of Foodborne Illnesses, Hospitalizations, and Deaths (United States, estimated annual)). To try to deal with foodborne illnesses, Congress passed the Food Safety Modernization Act of 2010, Public Law 111-353, giving the Food and Drug Administration (FDA) new powers to prevent outbreaks. For a summary of the act see Ibid., 8-9. Seemingly, inadequate appropriations and the FDA's attempt to impose user fees to help fund the law may undermine Congress's intent to improve the food safety system. Ron Nixon, "Law Aims to Prevent Food-Borne Illnesses, but Funding From Congress Falls Short,"' New York Times, April 8, 2015, A12.

${ }^{5}$ Mark Bittman, "A Chicken Without Guilt," New York Times, March 11 2012, SR1. In 2015, the U.S. Department of 
Agriculture proposed testing standards for chicken (and turkey) aimed at decreasing the rates of salmonella and other bacterial contamination. U.S. Department of Agriculture (DoA), News Release, “USDA Proposes New Measures to Reduce Salmonella and Campylobacter in Poultry Products,"' January 13, 2015; DoA, Food Safety Inspection Services, Changes to the Salmonella and Campylobacter Verification Testing Program, Federal Register 80:16 (January 26, 2015): 3940-3950. See also Tennille Tracy, "Poultry Rules Target Salmonella," Wall Street Journal, January 22, 2015, A3.

${ }^{6}$ Meat Atlas: Facts and figures about the animals we eat (Meat Atlas), Heinrich Böll Stiftung and Friends of the Earth Europe, January 2014, 26-27. See also American Public Health Association (APHA), Toward a Healthy Sustainable Food System, Policy Report Number 200712, November 6, 2007. For business efforts to end the practice of feeding antibiotics to livestock to enhance their growth see David Kesmodel, Jacob Bunge, and Betsy McKay, "'Shoppers Push Meat Industry To wean Itself off Drugs," Wall Street Journal, November 4, 2014, A1. 
7 An Pan et al., "Red Meat Consumption and Mortality:

Results from 2 Prospective Cohort Studies," Archives of Internal Medicine 172:7 (April 9, 2012): 555-563. See also Nicholas Bakalar, "Risks: More Red Meat, More Mortality," New York Times March 12, 2012, D6. For a critique of this research, see Nina Teicholz, The Big Fat Surprise: Why Butter, Meat, and Cheese Belong in a Healthy Diet (New York: Simon \& Schuster, 2014), 109-111.

${ }^{8}$ National Cholesterol Education Program, Third Report of the National Cholesterol Education Program (NCEP). Expert Panel on Detection, Evaluation, and Treatment of High Blood Cholesterol in Adults (Adult Treatment Panel III) Final Report, NIH Publication No. 02-5215, September 2002, II-1. ${ }^{9}$ The U.S. Department of Agriculture and U.S. Department of Health and Human Services, Dietary Guidelines for Americans 2010 (Dietary Guidelines), $7^{\text {th }}$ ed., December 2010, 21. ${ }^{10}$ For a summary of studies finding that high LDL cholesterol levels are uncorrelated to whether or not people had heart attacks see, e.g., Rodney A. Hayward and Harlan M. Krumholz, "Three Reasons to Abandon Low-Density Lipoprotein Targets: An Open Letter to the Adult Treatment Panel IV of the National Institutes of Health,'" 
Circulation 5:1 (January 2012): 2-5. Teicholz, Big Fat Surprise, 316-326 provides a summary and critique of the cholesterol research. The 2015 Dietary Guidelines Advisory Committee did not bring forward any recommendation to limit daily cholesterol intake "because available evidence shows no appreciable relationship between consumption of dietary cholesterol and serum cholesterol."' Scientific Report of the 2015 Dietary Guidelines Advisory Committee (2015 Dietary Guidelines Advisory Committee Report), Advisory Report to the Secretary of Health and Human Services and the Secretary of Agriculture, February 2015, Part D. Chapter 1, 17. See also Anahad 0'Connor, "Panel Calls for Less Sugar and Eases Cholesterol Restrictions," ${ }^{\prime}$ New York Times, February 20, 2015, A13.

${ }^{11}$ U.S. Department of Agriculture and U.S. Department of Health and Human Services, Nutrition and Your Health: Dietary Guidelines for Americans, Home and Garden Bulletin No. $228,1980,11-12$.

12 Dietary Guidelines, 24.

${ }^{13}$ Ibid., 24-25. See also Dariush Mozaffarian, Renata Micha, Sarah Wallace, "Effects on Coronary Heart Disease of Increasing Polyunsaturated Fat in Place of Saturated 
Fat: A Systematic Review and Meta-Analysis of Randomized Controlled Trials' PLoS Medicine 7:3 (March 2010): e1000252.doi 10.1371/journal.pmed.1000252, concluding that a shift to greater polyunsaturated fat consumption would significantly reduce the rates of coronary heart disease. ${ }^{14}$ Dietary Guidelines, 34, 38. For a discussion of the influence of manufacturers of processed food on the Dietary Guidelines see Michael Moss, Salt Sugar Fat: How the Food Giants Hooked US (New York: Random House, 2013), 219-221. ${ }^{15}$ Multiple Risk Factor Intervention Trial Research Group, “Multiple Risk Factor Intervention Trial: Risk Factor Changes and Mortality Results," Journal of the American Medical Association 248:12 (September 24, 1982): 1465-1477. The results of the Women's Health Initiative studies, which enrolled 49,000 women, ages 50 to 79, found that a low fat diet did not significantly reduce the risk of heart disease or cancer. Barbara V. Howard et al., "Low-Fat Dietary Pattern and Risk of Cardiovascular Disease," Journal of the American Medical Association 295:6 (February 8, 2006): 655-666; Shirley A.A. Beresford et al., "Low-Fat Dietary Pattern and Risk of Colorectal Cancer,"' Journal of the American Medical Association 295:6 (February 8, 2006): 643- 
654; Ross L. Prentice et al., “'Low-Fat Dietary Pattern and Risk of Invasive Breast Cancer,"' Journal of the American Medical Association 295:6 (February 8, 2006): 629-642; Ross L. Prentice et al., "Low-Fat Dietary Pattern and Cancer Incidence in the Women's Health Initiative Dietary Modification Randomized Controlled Trial,"' Journal of the National Cancer Institute 99:20 (October 17, 2007): 15341543. See also Glen D. Lawrence, "Dietary Fats and Health: Dietary Recommendations in the Context of Scientific Evidence,"' Advanced Nutrition 4:3 (May 2013): 294-302 and Gina Kolata, "'Low-Fat Diet Does Not Cut Health Risks, Study Finds,"' New York Times, February 8, 2006, A1. ${ }^{16}$ One of the meta-analytical papers, which looked at all the data from epidemiological (observational) studies, in which investigators profile subjects and then watch them over a period of time to observe health outcomes, concluded that saturated fat was not associated with an increased risk for heart disease or stroke. Patty $W$. Siri-Tarino et al., "Meta-analysis of prospective cohort studies evaluating the association of saturated fat with cardiovascular disease," American Journal of Clinical Nutrition 91:3 (March 2010): 535-546. A paper examining 
all other evidence, including clinical trials, concluded that eating saturated fat is healthier than eating carbohydrates. Patty W. Siri-Tarino et al., "Saturated fat, carbohydrates, and cardiovascular disease," American Journal of Clinical Nutrition 91:3 (March 2010): 502-509. Another review of all studies of the low-fat diet concluded there is "no probable or convincing evidence" that a high level of fat in the diet causes coronary heart disease or cancer. Food and Agriculture Organization of the United Nations (FAO), Fats and Fatty Acids in Human Nutrition: Report of an expert consultation 10-14 November 2008, FAO Food and Nutrition Paper 91, 2010, 13. However, another meta-analysis of prospective studies supported the hypothesis that high consumption of red meat and processed meat was associated with an increased risk of colorectal cancer. Susanna C. Larsson and Alicja Wolk, "Meat consumption and risk of colorectal cancer: A meta-analysis of prospective studies, '" International Journal of Cancer 119:11 (December 1, 2006): 2657-2664.

17 Rajiv Chowdhury et al., "Association of Dietary, Circulating, and Supplement Fatty Acids With Coronary Risk," Annals of Internal Medicine 160:6 (March 18, 2014): 
398-406 and "Correction," Annals of Internal Medicine 160:6 (March 18, 2014) <wWw.annals.org>. See also Mark Bittman, "Butter Is Back," New York Times, March 25, 2014, A23.

${ }^{18}$ Dariush Mozaffarian, "The Great Fat Debate: Taking the Focus Off of Saturated Fat," Journal of the American Dietetic Association 111:5 (May 2011): 665. However, the prohibition against saturated fat and its replacement with polyunsaturated fats remain strong. Dietary Guidelines Advisory Committee, Report of the Dietary Guidelines Advisory Committee on the Dietary Guidelines for Americans, 2010, To the Secretary of Agriculture and the Secretary of Health and Human Services, May 2010, 4, 13-14 and Robert H. Eckel et al., “2013 AHA/ACC Guideline on Lifestyle Management to Reduce Cardiovascular Risk: A Report of the American College of Cardiology/American Heart Association Task Force on Practice Guidelines (2013 AHA/ACC Report),'" Circulation 63:25:Part B (July 2014): 2960-2984, at 29692970. The 2015 Dietary Guidelines Advisory Committee Report, Part D. Chapter 1, 17, concurred with the 2013 AHA/ACC Report that "saturated fat intake exceeds current recommendations in the United States and that lower levels 
of consumption would further reduce the population level risk of [cardiovascular disease]." For the scientific evidence on the relationship between the intake of saturated fat and the risk of cardiovascular disease see Ibid., Part D. Chapter 6, 11-17, particularly the replacement of saturated fat with polyunsaturated fat. For a critique of these guidelines and the prohibition against saturated fat see Teicholz, Big Fat Surprise, 321-322 and Nina Teicholz, "The Government's Bad Diet Advice," New York Times, February 21, 2015, A19. But see Dean Ornish, "The Myth of High-Protein Diets," New York Times, March 23, 2015, A19.

19 Teicholz, Big Fat Surprise, 326. Other critiques of diet-heart hypothesis include Gary Taubes, "What if It's All Been a Big Fat Lie?, New York Times Magazine, July 7, $2002,22-27,34,45,47$.

${ }^{20}$ FAO, How to Feed the World in 2050, 2009, 2, 5 . Some researchers see an 80 percent probability that the world's population may rise to as much as 12.3 billion by 2100 , thereby putting more pressure on land and water, especially if the food system cannot withstand the effects of climate change. Patrick Gerland, “'World population stabilization 
unlikely this century,"' Science 346:2606 (October 10, 2014): 234-237. For a critique of the world population growth estimates see Nicholas Eberstadt, “The new population boom could easily be a dud," American Enterprise Institute, September 22, 2014 $<$ wW.aei.org/publication/the-new-population-boom-couldeasily-be-a-dud> and Floyd Norris, "Population Growth Forecast From the U.N. May Be Too High,"' New York Times, September 20, 2013, B3.

${ }^{21}$ FA0, How to Feed, 2.

22 Jonathan Foley, "A Five-Step Plan to Feed the World," National Geographic 225:5 (May 2014): 27-57, at 45 .

${ }^{23}$ FAO, Livestock's Long Shadow--Environmental Issues and Options, 2006, 74 .

24 Ibid., 125.

${ }^{25}$ Arjen Y. Hoekstra, "The water footprint of food," in Water for Food, Swedish Research Council for Environment, 2008, 49-60, at 53. FA0, Livestock's Long Shadow, 128-135, analyzes water use for drinking and servicing animals, product processing and feed production. See also Meat Atlas, 28-29. 
${ }^{26}$ FAO, Livestock's Long Shadow, 135-169, analyzes water pollution, including livestock waste, wastes from livestock processing, pollution from feed and fodder production, and livestock's land use impact on water cycles. See also, APHA, Toward.

${ }^{27}$ Hanna L. Tuomisto and M. Joost Teixeira de Mattos, "Environmental Impacts of Cultured Meat Production," Environmental Science \& Technology 45:4 (July 15, 2011): 6117-6123, at 6117, presented a life cycle analysis based on a number of assumptions.

${ }^{28}$ Intergovernmental Panel on Climate Change (IPCC), Climate Change 2014: Synthesis Report, Approved Summary for Policymakers, November 1, 2014 (Synthesis Report), SPM-3 and 1. See also Justin Gillis, "U.N. Panel Issues Its Starkest Warning Yet on Global Warming, "' New York Times, November 3, 2014, A6.

${ }^{29}$ IPCC, Synthesis Report, SPM-3 and 1.

${ }^{30}$ Ibid., SPM-8, 10-12.

${ }^{31}$ Ibid., SPM-9 to SPM-11, 12-16.

${ }^{32}$ FAO, Livestock's Long Shadow, 112. See also FA0, Press Release, "Livestock a major threat to environment: Remedies urgently needed,'" November 29, 2006. For a 
critique of FAO estimates, including overlooked livestock respiration, and land use as well as undercounted methane, among other undercounted categories, see Robert Goodland and Jeff Anhang, "Livestock and Climate Change," World Watch 22:6 (November/December 2009): 10-19, concluding that livestock and their byproducts account for at least 51 percent of the annual worldwide greenhouse gas emissions. ${ }^{33}$ FAO, Livestock's Long Shadow, 82. ${ }^{34}$ Ibid., 112, 114.

35 Tuomisto and Teixeira de Mattos, “Environmental Impacts," 6117, obtained these figures using an algaebased source of nutrients and energy for muscle cell production of in vitro meat. ${ }^{36}$ See, e.g., Richard S. Lindzen, "The Climate Science Isn't Settled,"' Wall Street Journal, December 1, 2009, A19 and Richard S. Lindzen, "There Is No 'Consensus' on Global Warming,"' Wall Street Journal, June 26, 2006, A14. See also Bjorn Lomborg, Cool It: The Skeptical Environmental's Guide to Global Warming (New York: Knopf, 2007). ${ }^{37}$ IPCC, Synthesis Report, SPM-3 and 1. ${ }^{38}$ Nicholas Lewis and Judith A. Curry, "The implications for climate sensitivity of AR5 forcing and heat uptake 
estimates,"' Climate Dynamics (online), September 25, 2014, DOI 10.1007/s00382-014-2342-y. See also Judith Curry, "The Global Warming Statistical Meltdown," Wall Street Journal, October 10, 2014, A15. But see Justin Gillis, “2014 Breaks Heat Record, Challenging Global Warming Skeptics," New York Times, January 17, 2015, A1 and Robert Lee Hotz, "Group Say '14 Was World's Warmest,"' Wall street Journal, January 17-18, 2015, A6.

${ }^{39}$ However, the mortality rates for chickens raised in the cage-free system seemingly are double those raised in a regular or large cage system. The higher mortality rates stem, in part, from hens cannibalizing one another or excessive pecking. David Kesmodel, "Do Cage-Free Chickens Produce Better Eggs?,'" Wall Street Journal, March 19, 2015, B3. Egg farmers must also respond to new state laws and food company requirements for more space for chickens. See David Kesmodel, "Flap Over Eggs: Whether to Go 'CageFree',"' Wall Street Journal, March 16, 2015, B1. ${ }^{40}$ To reduce the antibiotic-resistant bacteria created by America's agricultural industry, in 2015, the Obama Administration released the National Action Plan for Combatting Antibiotic-Resistant Bacteria. The White House, 
Office of the Press Secretary, Fact Sheet: Obama Administration Releases National Action Plan to Combat Antibiotic-Resistant Bacteria, March 27, 2015 and The White House, National Action Plan for Combating AntibioticResistant Bacteria, March 2015. See also Ed Silverman, "Can U.S. Stop the Spread of Superbugs?," Wall street Journal, April 8, 2015, B3. 
3. Plant-Based Cheese Substitutes: Lyrical Foods

For years, companies have tried to develop

alternatives to cheese, which people increasingly avoid for health reasons: it raises the bad cholesterol level; it has a high saturated fat content; they are lactose intolerant, that is, they are unable to digest lactose, a sugar found in milk; or they are allergic to milk, where the presence of milk proteins trigger an immune reaction. However, companies have found it difficult to develop perfect cheese substitutes with comparable taste and texture.

Vegans, those who abstain from consuming animal products, not only meat but also animal-derived substances, such as dairy products, face a forbidden food that taunts and tests their plant-based perseverance. That food is cheese. This is partly because cheese is so ubiquitous in food preparation, and for many, partly because of fondly remembered cheese-based childhood comfort foods.

The journey of Tal Ronnen, the chef behind Lyrical Foods' Kite Hill cheeses, profiled in this chapter, spans old-world cheesemaking, contemporary biotechnology, and venture capital funding. Culinary entrepreneurship as exemplified by Ronnen, combines environmental and vegan 
ethics, a commitment to flavor, and a belief that technology and money can improve the world. Non-Dairy Cheese Substitutes

For years, established companies have produced and sold vegan alternative, non-dairy cheeses, such as Daiya, Teese, and Tofutti. ${ }^{1}$ Although intended as cheese replacements, they lack the texture, smell, and taste of dairy cheese, at least right out of the package. Best melted on food, these non-dairy cheeses remain a niche product.

These vegan cheese alternatives are typically made from soybeans, including tofu, soymilk, or soy protein isolate, but also from a variety of non-dairy ingredients, such as rice and almonds. As a result, they are skimpy in nutrients, such as calcium. Also, up to now, commercial nut-based cheeses often taste strongly nut-flavored, with a rather gritty texture. They do not resemble anything like an oozy brie.

Many dairy analogs are made with oils, such as coconut oil, making them high in fat, and highly processed ingredients, such as casein, which is extracted from dried 
milk proteins. The use of casein makes them unsuitable for vegans, who eschew all animal products, including milk.

\section{Lyrical Foods}

Founded in 2011, Lyrical Foods, Inc. (Lyrical) produces non-dairy cheeses under the brand name Kite Hill Foods. ${ }^{2}$ It has three co-founders: Tal Ronnen, a vegan chef; Stanford University biochemistry professor Patrick 0. Brown, a molecular biologist and physician, and a member of both the Institute of Medicine and the National Academy of Sciences; and Monte Casino, a culinary instructor. Ronnen's quest to make vegan cheeses worthy of a great chef began by visiting the cheese-making rooms at Le Cordon Blue Boston. There he met veteran instructor, Casino. Traditional cheesemaking involves souring dairy milk and then adding renin, an enzyme, to thicken the protein and fat in the milk. Casino realized that nut milk has the same four components as dairy milk, namely sugar, protein, fat, and water, and thus should thicken similarly. 
Ronnen's friend, Brown, had a project underway to develop nut milks for vegan cheesemaking. Connected by Ronnen to Brown, Casino started tinkering with samples of Brown's nut milks.

The trio took three years to develop cheeses out of an almond and macadamia nut milk base, together with a naturally-occurring enzyme found in plants and microbes, a bacteria started culture enhanced with a thickener, and salt, using the techniques of artisanal cheesemaking.

Traditional Cheesemaking

Traditional cheesemaking requires milk's protein, casein, and fat content to coagulate--curdle. Milk is first acidified by adding bacteria to convert the sugars into lactic acid requisite to form the softer curds characteristic of cheeses, such as cottage cheese. More rubbery, aged cheeses, such as cheddar, require added enzymes to achieve the desired taste and texture. For nearly all U.S. cheeses, coagulation is achieved with enzymes from one of two microbial sources. Today, only a small percentage, about 3 percent, of the cheese produced 
in the United States use calf rennet, an enzyme derived from the stomach linings of very young calves.

Lyrical's Cheesemaking

Lyrical produces cheeses by inducing the enzymatic curdling of non-dairy milks. Unlike other non-dairy cheeses, the company does not use any artificial ingredients, starches or gums.

Lyrical perfected almond nut milk for its cheeses over many months of recipe testing and visits to some almond farms in California's San Joaquin Valley. After testing some twenty seven almond varietals, the team selected one to grind and triple-filter into silky white almond milk. Given the seasonal fluctuations in tree nuts' flavors and textures, the company custom blends each batch of almond nut milk for every cheese it makes. It then pasteurizes and inoculates the nut milk with a naturally occurring enzyme and a specially developed lactose-free culture. The firm has developed a technique that makes the nut milk proteins behave like those in dairy milk, compensating for a lack of milk protein, casein, and lactose so that the nut milk coagulates and forms a curd, which is then 
concentrated and cultured similar to dairy cheese. It allows the mixture to coagulate slowly to let the curd fully develop the unique flavor and character that defines each of its cheeses. Eventually, employees distribute the curd by hand into traditional cheese molds where it is aged. ${ }^{3}$ Making its soft cheese products is a relatively long process as aging generally requires several days to a month or more.

Lyrical's Kite Hill Products

Lyrical's products are sold under the Kite Hill brand. Kite Hill's cheeses include several "soft fresh" varieties. ${ }^{4}$ These include: a soft and creamy mozzarellastyle cheese and a semi-soft cheese crusted with paprika and fennel pollen. The soft and creamy cheese also comes in a chive, dill, and truffle flavor. The firm produces a ricotta cheese, smooth and moist, a plain and a chive cream cheese, and has several other soft cheeses in development.

Kite Hill's Distribution

Sold in puck-shaped packaging, Lyrical currently distributes its Kite Hill cheeses exclusively through whole 
Foods Market stores, initially in select locations in 2013. Beginning in 2014, more Whole Foods stores across the country offered Kite Hill cheeses. These cheeses are the first plant-based cheese whole Foods sells in its cheese department, with other fine fromage, rather than in its regular dairy section. Lyrical also sells Kite Hill cheeses directly to selected restaurants.

Financing Lyrical Foods

Given the rich texture, mouthfeel, and flavor of its Kite Hill cheeses, Lyrical can sell to more than just vegan consumers. The size of the potential market has attracted funding from venture capital firms. In 2014, Lyrical secured an investment from Khosla Ventures. With these funds, Lyrical built a production facility in Haywood, California. ${ }^{5}$

Looking To The Future

Lyrical co-founder Patrick Brown sees a much bigger market than just cheese. He wants to give people the taste and nutritional benefits of foods from animals, particularly meat, without the negative health and 
environmental impacts. To make "food for people who are comfortable eating meat and who want to continue eating meat, ${ }^{\prime 6}$ Brown organized Impossible Foods, Inc. in 2011, which is examined in Chapter 6.

${ }^{1}$ Ask EN, “There's Nothing Cheesy about These Alternatives,"' Environmental Nutrition 35:5 (May 2012): 7. ${ }^{2}$ Kite Hill, "About Kite Hill: Our Story" <wWW.kitehill.com/about.html> (September 25, 2014) and "About Kite Hill: Our Team"'<www.kite-hill.com/about.html> (September 25, 2014). See also Daniel Duane, "Engineering the Future of Artisanal Vegan Cheese,"' Food \& Wine, November 2013, $84,86-87$.

${ }^{3}$ Kite Hill, "About Kite Hill: Making Kite Hill" <WWW.kite-hill.com/making.html> (September 25, 2014) and "About Kite Hill: FAQs" <WWW.kite-hill.com/faq.html> (September 25, 2014). Lyrical's patents include United States Patent Application Publication, Methods and Compositions For Consumables, Pub. No US 2014/0127358 A1, Pub. Date May 8, 2014. The World Intellectual Property Organization also published Lyrical's patent application. US Fed News, "WIPO Publishes Patent of Lyrical Foods, Brown Patrick, Casino Monte, Voccola Lynn S., Varadan 
Ranjani, For 'Methods and Compositions For Consumables' (American Inventors) January 21, 2013 <Factiva>. ${ }^{4}$ Kite Hill, "Soft Fresh Original" <wWW. kitehill.com/softfresh.html> (September 25, 2014), "Soft Fresh Truffle \& Chive"' <wWw.kite-hill.com/truffledill.html> (November 11, 2014), "Soft Ripened" <wWW.kitehill.com/softripened.html> (November 11, 2014), "Ricotta" <WWW.kite-hill.com/ricotta.html> (November 11, 2014). "Cream Cheese Plain" <www.kite-

hill.com/creamcheeseplain.html> (April 7, 2015), and "Cream Cheese Chive" <www.hite-

hill.com/creamcheesechive.html> (April 7, 2015). For review of Kite Hill cheeses see Choosing Raw, "A New Kind of Non-Dairy Cheese: Artisanal Vegan Nut Milk Cheeses from Kite Hill,"' July 3, 2013 <wWw. choosingraw.com/a-new-kindof-non-dairy-cheese-artisanal-vegan-nut-milk-cheeses-fromkite-hill>; Duane, "'Engineering," 87; Chelse Morse, "Genius and Delicious: New Vegan Cheese," Food \& Wine, September 23, 2013 $<W W W$. foodandwine.com/blogs/2013/9/23/genius-and-deliciousnew-vegan-cheese>. 
${ }^{5}$ Khosla Ventures, "Our Portfolio,"

$<$ wW. khoslaventures.com/portfolio?type=Agriculture\%2Food $>$ (September 10, 2014).

${ }^{6}$ Patrick Brown quoted in Michael Hanlon, "Fake meat: is science fiction on the verge of becoming fact?," Guardian (London), June 22, 2012

<wWW. theguardian. com/science/2012/jun/22/fake-meat scienctific-breakthroughs-research>. 
4. Plant-Based Egg Substitutes: Hampton Creek

For years, companies have tried to develop

alternatives to eggs, mainly for health reasons. Four decades ago the American Heart Association, among other groups, discouraged people from eating eggs because it was thought that cholesterol-rich yolks would raise the risk of heart disease. Now, a reasonable consumption of eggs, such as one egg yolk per day, according to the Dietary Guidelines for Americans 2010, "does not result in increased blood cholesterol levels, nor does it increase the risk of cardiovascular disease in healthy people. ${ }^{\prime 1}$ Thus, today people avoid eggs for environmental, food safety, and animal welfare reasons, specifically, the traditional egg production system, which involves keeping hens packed into dirty cages and forcing them to produce eggs to the point of exhaustion. It is also inefficient compared to what might be done with plants.

It is a challenge, however, to find egg substitutes with comparable texture and flavor, while providing essential functions for cooking, such as the ability to bind foods and give them a satisfying mouthfeel. Current egg replacers, such as Ener-g Egg Replacer, which is vegan 
and gluten free, as well as vegan (egg-free) mayonnaise brands, including Vegenaise, Miso Mayo, and Egg Free Mayo, remain niche products. They have not achieved a high degree of household penetration.

This chapter profiles Hampton Creek's response to consumer demands for products, which are better for animal welfare and the environment. Hampton's lead product, its eggless Just Mayo condiment, has won shelf space at retailers, including Whole Foods Market and Wal-Mart. It is marketed as a mainstream brand: healthy, inexpensive, and good for everyone.

\section{Hampton Creek}

Hampton Creek Foods, Inc. (Hampton Creek), was cofounded in 2011, by Joshua (Josh) Tetrick, who currently serves as its chief executive officer, with Joshua (Josh) Balk. The firm wants to revolutionize the food system by moving the world from animal-based foods. It seeks to create by healthier, more sustainable, humanely produced, if not cheaper and tastier, plant-based alternatives. ${ }^{2}$ This desire to change the food system motivated Tetrick to start the company. Balk, Tetrick's long time 
friend then working at The Humane Society of the United States told him about intensive commercial egg-laying facilities and inspired him to do better. Hearing about the carbon-intensive chicken raising process and the bad conditions in which most hens are kept opened Tetrick's eyes to how he might change the world through food. Seeking a plant-based, more affordable substitute for eggs, Hampton Creek was born, named after Balk's dog. ${ }^{3}$ The company has at its mission "to decrease by 30 percent the number of egg-laying hens in battery cage facilities during the next five years [2013-2018]" and "end animal suffering in the egg industry. ${ }^{\prime 4}$

The company began its quest to achieve its mission by sourcing plants worldwide. In building the firm, Tetrick quickly hired a protein chemist, a food scientist, a sales executive from Heinz, and a contestant from the television show, Top Chef.

Hampton Creek focuses on discovering vegetable proteins that replicate specific functions in both animalbased foods and in food preparation. It has examined some 7,000 plants and come up with eleven desirable proteins, seven of which are allowed in food by the U.S. Food and 
Drug Administration. ${ }^{5}$ The company screened hundreds of varieties of yellow pea and used rapid prototyping technology to come up with pea properties that mimicked egg emulsion. For example, Canadian yellow pea (a type of split pea) protein emulsifies the oil and water in the firm's mayonnaise product.

To come up with better plant-based products, Hampton Creek relies more on computational science, not food science. The firm maintains an exhaustive database containing thousands of plant varieties, which correlates between their biochemical properties and functionalities, such as emulsion, coagulation, and aeration. The database facilitates the fast screening of plants from a molecular perspective. By classifying a plant's molecular properties and using the firm's predictive models, it can predict the kitchen use of a given plant species. As one journalist put it, "Food 2.0 companies [such as Hampton Creek] are using computational algorithms to analyze hundreds of thousands of plant species to find out what compounds can be stripped out and recombined to create what they say are more delicious and sustainable sources of protein. ${ }^{\prime 6}$ According to Tetrick, "Our vice president of data was head 
of data analytics for Google Maps and YouTube, and our last seven hires have been data scientists. We can run our experiments in the cloud rather than always having to grind ingredients up and trying them out in a recipe. ${ }^{\prime 7}$

Hampton Creek's Products

Hampton Creek uses plants, more specifically peas, to make its yellowish egg powder substitute, Beyond Eggs, which has properties similar to conventional chicken eggs. Its egg substitute is free of cholesterol, sugar, salt, allergens, and avian flu, and contains only a limited amount of saturated fat. Its technology platform enables the firm to produce a healthier product at a lower cost than traditional eggs. With conventional egg production costs rising, Beyond Eggs, its business-to-business product, presently costs about 18 percent less than real eggs. ${ }^{8}$ In short, it's better for food manufacturers' bottom line, not merely their animal welfare or environmental ethic.

Hampton Creek's Distribution 
Big food producers want to use a cheap, convincing egg substitute in their products. The company also thrives as a consumer brand in supermarkets.

In late 2013-early 2014, the company signed partnership agreements with six fortune 500 companies, including some of the world's largest food manufacturers and retailers. ${ }^{9}$ These firms use Beyond Eggs, a plant-based egg replacer, for baked goods and other food products, such as pasta.

Later in 2014, Hampton Creek signed a partnership agreement with the Compass Group, the world's largest foodservice company, to provide a replacement for its conventional chocolate chip cookies. The arrangement will enable Hampton Creek to bring its Just Cookies, a healthier cookie, to millions of customers. The plant-based product binds other ingredients like an egg in cookie dough. Each case of Just Cookies, consisting of 210 cookies, uses 2, 000 fewer gallons of water, requires seven fewer square meters (about 70 square feet) of land, and contains 3,000 fewer milligrams (mg) of cholesterol or zero mg per cookie. ${ }^{10}$ Subsequently, in 2015, the Compass Group USA signed an even more significant distribution deal with Hampton 
Creek. ${ }^{11}$ Under the arrangement, Foodbuy, the Compass Group's procurement company, the largest foodservice and hospitality group purchasing company in North America, will add Just Mayo, along with Just Cookies, to the products it sells to institutional food providers, such as health care organizations, universities, and senior living facilities. Recognizing the importance of this partnership, Tetrick stated, " $[\mathrm{W}] \mathrm{e}^{\prime}$ re tapping into this powerful, powerful infrastructure that determines what ends up on a lot of plates. This extends the reach of our products beyond anything we've done before. ${ }^{\prime 12}$

Hampton Creek's Just Mayo, an egg-free mayonnaise substitute, and its Just Cookies, an egg and milk-free cookie dough, found their way into supermarkets. The firm sells its flavored sandwich spreads under the name Just Mayo with a term describing the added flavors, such as Just Mayo Garlic. Just Cookies comes in four flavors: chocolate chip; sugar; oatmeal raisin; and peanut butter. It is working on developing a gooey egg-free mix, Just Scramble, designed to replicate scrambled eggs and other plant-based alternatives to pasta, ice cream, and salad dressings. 
The prepared food counters at whole Foods started using Just Mayo in September 2013. ${ }^{13}$ Quickly, Hampton Creek's Just mayo brand of eggless mayonnaise went on many Whole Food's shelves nationwide. Other supermarkets nationwide lined up in 2014, including Safeway, ShopRite, and Kroger as well as Target, Wal-Mart, DollarTree, and selected Costco Wholesale stores, to carry a shelf-stable non-refrigerated version of Just Mayo. ${ }^{14}$

Hampton's manufacturing partner produces Just Mayo. United Natural Foods, a distribution company, distributes the product to whole Foods and other stores across the United States.

Financing Hampton Creek

Tetrick invested some $\$ 37,000$ of his own funds in the company in 2011. With its egg substitute widely used in mayonnaise and cookies, Hampton Creek easily raised capital from outside investors, who recognized what plant-based proteins could deliver. ${ }^{15}$ Initially, the firm obtained a $\$ 2$ million equity investment from Khosla Ventures LLC. Khosla provided $\$ 500,000$ in seed funding and subsequently invested $\$ 1.5$ million, which was used to expand corporate 
headquarters and add additional employees. Also in 2011, Hampton Creek raised a $\$ 1$ million equity investment from Founders Fund, a venture capital firm founded by Peter Thiel and other former PayPal executives. Thiel seeks to back companies with big, ambitious plans. Two years later, in 2013, AME Cloud Ventures, the venture capital arm of Yahoo co-founder Jerry Yang, which focuses on technologyheavy companies, made a $\$ 1$ million equity investment.

Then in 2014, Hampton Creek garnered \$23 million in a Series B convertible preferred stock financing round. Horizon Ventures Ltd., which manages the investments of $\mathrm{Li}$ Ka-shing, the wealthiest man in Asia, focused on disruptive, technology-focused startups, led the round, pumping in $\$ 15.5$ million. Other investors included The Collaborative Fund, Tom Steyers' Eagle Cliff Partners LLC, and several individual investors, including Bill Gates, Google vice president Jessica Powell, and Scott Banister, a prominent angel investor. Khosla Ventures, an early investor, also participated in this round. Hampton Creek used these funds to accelerate its growth in North America, expand its operations in Asia, pursue strategic partnerships, and grow its team. ${ }^{16}$ 
In December 2014, the firm raised an additional $\$ 90$ million in a Series C financial round, bringing the company's total funding to nearly $\$ 120$ million. Horizons Ventures and Khosla Ventures co-led the round. New investors included Salesforce CEO Marc Benioff and Facebook co-founder Eduardo Saverin. The funds will go toward enhancing the firm's technology, such as better laboratory automation, general corporate expenses, and expansion in Western Europe and Asia. ${ }^{17}$

Awards Received

Hampton Creek received the Best of What's New 2013:

100 Innovations That Will Shape the Future Award by Popular Science for its plant-based egg substitute. ${ }^{18}$ The company was also named one of Entrepreneur Magazine's 100 Brilliant Companies in 2014, one of that magazine's 25 most innovative consumer and retail brands in 2014, and number 36 of $\mathrm{CNBC}^{\prime} \mathrm{s}$ Top 50 Disruptors. ${ }^{19}$ Inc. magazine named Tetrick to its 35 under 35 list. ${ }^{20}$

Success Leads To Litigation

In response to Hampton Creek's inroads in a traditional food category--mayonnaise--in october 2014 
Unilever PLC, the maker of Hellmann's and Best Foods brands of mayonnaise, which controls 45 percent of the U.S. market, sued Hampton. ${ }^{21}$ Unilever accused Hampton of false advertising, specifically, for calling its eggless spread "mayo," and unfair competition. Marking one in a series of likely battles between established food companies, actually food conglomerates, facing competition from startups, luring consumers away from their traditional products, such as mayonnaise a $\$ 2$ billion per year market in the U.S., Unilever asserted that Just Mayo's label, which features a white egg cracked by a pea shoot, violates federal law governing trademarks and advertising. According to Unilever, the label gave consumers the false impression that the product contains eggs. Unilever also maintained that Just Mayo lacked testing to back up the claim that it beat Hellmann's in a taste test. Furthermore, Unilever claimed Just Mayo failed to meet the U.S. Food and Drug Administration's (FDA's) definition of mayonnaise, which must contain egg-yolk ingredients and a minimum percentage of oil, 65 percent by weight. ${ }^{22}$ In addition to seeking compensatory and punitive damages, Unilever demanded that Hampton Creek change the label of 
its Just Mayo product, recall the product and promotional materials, and stop claiming superior tastes.

Recognizing that its lawsuit faced an uphill battle, Unilever dropped the suit, ${ }^{23}$ after it became a public relations disaster. Hampton Creek never claimed its product was mayonnaise. Also, Unilever marketed products as mayonnaise that did not meet the FDA's definition. Raising the prospect that Unilever had "unclean hands," Hampton Creek identified numerous changes to Hellmann's website in an attempt to rewrite history and characterize Unilever products as mayonnaise dressing. ${ }^{24}$

From a policy perspective, the FDA's definition, more technically, the standard of identity, of mayonnaise reflects an outdated regulation from 1957, decades before vegan mayonnaise. It needs updating. As Tetrick stated: "We've been going back and forth with them [the Food and Drug Administration] because the simple fact that this has happened speaks to the larger issue, which is we need for our regulatory framework to be more in line with the way we hope people are starting to eat. ${ }^{\prime 25}$

Looking To The Future 
About one third of conventional chicken eggs wind up as ingredients in food products, such as mayonnaise and baked goods. Currently, there is a $\$ 6$ billion market for these egg ingredients globally. ${ }^{26}$ It seems likely that Hampton Creek's plant-based egg products will disrupt at least the global egg ingredient industry, but not as quickly as its hopes. Its egg ingredient substitutes appeal to vegans, those with egg allergies, and those concerned about animal welfare, the environment, and food safety. In the future, it strives to appeal to those, worldwide, who want more affordable, better tasting, healthier egg ingredient products, such as mayonnaise, and even scrambled eggs. It is a scalable, viable, global solution.

However, Hampton Creek has encountered some speed bumps along the way. In early 2015, the company laid off about one fifth of its workforce, about a dozen of its 65 employees. Several more employees left voluntarily through a severance offer the firm extended. Shrouded in secrecy, allegedly some were dismissed for performance reasons and others for being negative. However, it was unusual for 
layoffs to occur at a startup so soon after raising $\$ 90$ million in December $2014 .^{27}$

Undeterred, Tetrick, like Patrick Brown, has a bigger mission. They both want to create a new category of hyper efficient protein sources, among other food products, from plants. In implementing this goal, they want a better way to feed the world, with the best food accessible to average people. Their efforts have attracted not only savvy, bigname investors but also food manufacturers as well as health and environmentally-oriented consumers.

${ }^{1}$ U.S. Department of Agriculture and U.S. Department of Health and Human Services, Dietary Guidelines for Americans 2010, $7^{\text {th }}$ ed., December 2010, 27. This guideline is in line with what research studies have shown. See, e.g., Frank B. Hu et al., "A Prospective Study of Egg Consumption and Risk of Cardiovascular Disease in Men and Women," Journal of American Medical Association 281:15 (April 21, 1999(: 1387-1394 (consuming up to one egg daily did not raise the risk of heart disease or stroke in healthy adults) and Ying Rong et al., "Egg consumption and risk of coronary heart disease and stroke: dose-response meta-analysis of prospective cohort studies,"' British Medical Journal 2013; 
346: e8539 doi: 10.1136/bmj.e8539. See also "'Ask Well,"' New York Times, November 18, 2014, D4. Jang Yel Shin et al., "Egg consumption in relation to risk of cardiovascular disease and diabetes: a systematic review and meta-analysis," American Journal of Clinical Nutrition 98:1 (July 2013): 146-159, concluded by suggesting that egg consumption is not associated with the risk of cardiovascular disease and cardiac mortality in the general population.

2 For background on Hampton Creek see Sarah Henry, "Cracking The Code," Washington Post, March 4, 2015, E1; John Bradley, “Hampton Creek's moonshot approach attracts astronomical backing,"' Nutrition Business Journal, January 1, 2015 <WWW. newhope360.com/node/1024371>; Erica Swallow, "Hampton Creek's Plan to Reimagine the Future of Food," Mashable, August 27, 2014 <WWW.mashable.com/2014/08/27/hampton-creek>; Nina Zipkin, "This Mega-Funded Startup Wants to Forget Chicken and Redefine the Egg,'" Entrepreneur, April 4, 2014 <wWW.entrepreneur.com/article/232793>; Elaine Watson, “Plant egg entrepreneur: 'We're not in business just to sell products to vegans in Northern California',,' 
FoodNavigator-USA, September 13, 2013 <wWw. foodnavigatoruse.com/People/Plant-egg-entrepreneur-We-re-not-inbusiness-just-to-sell-products-to-vegans-in-NorthernCalifornia>; Kyle VanHemert, "The Startup Lab Using Plants to Make Next-Gen Super Eggs, '" Wired, December 10, 2013 <WWW. wired.com/2013/12/inside-the-lab-thats-using-plantproteins-to-create-next-gen-super-eggs>; Ariel Schwartz, “'Inside the Company That's Producing The Most Realistic Eggs You'll Ever Taste,'" Fast Company, May 1, 2013 <WWW . fastcoexist . com/1681889/inside-the-company-thatsproducing-the-most-realistic-fake-eggs-youll-ever-taste\#1>. ${ }^{3}$ Annie Sciacca, "Meatless startups dream up alt foods,"' Upstart Business Journal Online, May 25, 2014 <Factiva>. 4 Josh Tetrick quoted in Karen E. Lange, "Best Laid Plans," All Animals (September/October 2013): 34-35, at 35.

5 Ted Greenwald, "The Next Startup Craze: Food 2.๑,"' Technology Review, May 7, 2014 <wWW. technologyreview. com/news/527056/the-next-startupcraze-food-20>

${ }^{6}$ Kate Murphy, "Rethinking Eating,"' New York Times, August 24, 2014, SR5. 
7 Ibid., See also Sarah Buhr, "How A Former Google Data Guy Could Change what we Eat For Breakfast,"' TechCrunch.com, July 3, 2014 <wW. techcrunch.com/2014/07/03/how-a-formergoogle-data-guy-could-change-what-we-eat-for-breakfast>. ${ }^{8}$ Schwartz, "Inside The Company." The ratio of energy input to food energy output for traditional eggs equals about 39 to 1 ; Hampton Creek's products maintain a 2 to 1 ratio. Ryan Mac, "Bill Gates' Food Fetish: Hampton Creek Foods Looks To Crack The Egg Industry,"' Forbes 192:9 (November 13, 2013): 66.

${ }^{9}$ Hampton Creek Foods (Hampton Creek), Press Release, “Hampton Creek, ${ }^{\mathrm{TM}}$ a technology company pioneering in food, announced today that it has completed a \$23 million Series B financing round,'" February 17, 2014.

10 Hampton Creek, "Hampton Creek Partners with World's Largest Foodservice Company for New Product--'Just Cookies','" August 6, 2014.

${ }^{11}$ Compass Group North America, Press Release, "Hampton Creek and Compass Group USA Announce Industry-Shape Partnership,"' February 19, 2015. See also Stephanie Strom, "Maker of Eggless Mayonnaise Signs Distribution Deal," New York Times, March 7, 2015, B2. 
12 Josh Tetrick quoted in Strom, "Maker."

${ }^{13}$ For how Hampton Creek gained access to Whole Foods distribution see Vanessa Wong, "How a Vegan Mayo Maker Bulks Up for Whole Foods,"' Bloomberg Businessweek.com October 22, 2013 <wWw. businessweek.com/articles/2013-1022/how-a-vegan-mayo-maker-bulks-up-for-whole-foods>. ${ }^{14}$ See, e.g., Maggie Hennessy, "Just Mayo Walmart deal just another step in 'making food better': Hampton Creek CEO,' Food Navigator-USA, August 12, $2014<w W W$. foodnavigatorusa. com/Manufacturers/Hampton-Creek-plant-based-mayosecures-Walmart-distribution> and James Temple, “Hampton Creek Strikes Kroger Deal to Bring Just Mayo to the Masses,"' May 2, 2014 <WW. recode.net/2014/05/02/hamptoncreek-strikes-giant-kroger-deal-to-bring-just-mayo-to-themasses $>$.

15 Thomson Reuters, Company Profile, Hampton Creek Foods, Inc., ID: C903783417, updated April 9, 2014 (update); Khosla Ventures, "Our Portfolio" $<$ WW. khoslaventures.com/portfolio?type=Agriculture\%2Ffood $>$ (September 10, 2014); Collaborative Fund, "Investments" <WW. collaborativefund.com/investments> (September 10, 2010); Anthony Ha, “Founders Fund Backs Its First Food 
Tech Startup, Hampton Creek Foods, With A \$1M Investment,"' TechCrunch, May 20, 2013

$<$ wWw. techcrunch. com/2013/05/20/founders - fund-backs-hamptoncreek-foods $>$.

${ }^{16}$ Hampton Creek, Press Release, “Hampton Creek Raises \$23M in Series B Funding,"' February 17, 2014. See also Jon Swartz, "Food tech startup gobbles up \$23 million in funding,"' USA Today, February 17, 2014 <wWw. usatoday.com/story/tech/2014/02/17/hampton-creekraises-23-million-in-series-b-funding/5433115> and Ryan Mac, “Egg Replacing Startup Hampton Creek Foods Raises \$23 Million From Asia's Richest Man and Yahoo Cofounder Jerry Yang,"' Forbes.com, February 17, 2014 <WWW. forbes.com/sites/ryanmac/2014/02/07/egg-replacingstartup-hampton-creek-foods-raises-23-million-from-asiasrichest-man-and-yahoo-cofounder>. ${ }^{17}$ Beth Kowitt, “More money for mayo: Food startup Hampton Creek raises $\$ 90$ million in funding, "' Fortune.com, December 18, 2014 <ww. fortune.com/2014/12/18/hamptoncreek-funding> and Ryan Mac, "Hampton Creek Backed By Benioff and Facebook Cofounder In $\$ 90$ Million Round, "' 
Forbes.com, December 18, 2014

<wWW. forbes.com/sites/ryanmac/2014/12/18/hampton-creek>.

${ }^{18}$ Michael Berk, "'26 $6^{\text {th }}$ Annual Best of What's New: 100

Innovations That Will Shape The Future," Popular Science, December 2013, 21-79, at 78 .

19 Jason Ankeny, "'The More Incredible Egg," Entrepreneur 42:6 (June 2014): 50; Ryan Caldbeck, “The 25 Most Innovative Consumer and Retail Brands," Entrepreneur, July 29, 2014 <WWW.entrepreneur.com/article/235945>; 2014 CNBC's Disruptor $50<$ <WW.cnbc.com/id/10134664\#> (November 9, $2014)$.

${ }^{20}$ Inc., “35 Under 35," 36:7 (July/August 2014): 46-54, at 52 and Christine Lagorio-Chafkin, "How to Change the World With 90 Million Pounds of Delicious Cookies,"' Inc. 36:7 (July/August 2014): 52-57. In 2015, Fast Company magazine named Hampton Creek as one of its most innovative companies, number two in the food category. Fast Company, "Most Innovative Companies By Sector," 194 (March 2015): $135-137$, at 136.

${ }^{21}$ Conopco, Inc. v. Hampton Creek, Inc., Complaint, United States District Court, District of New Jersey, Case 2:14cV-06856-WHW-CLW, October 31, 2014. See also Annie 
Gasparro, “Hellman's Seeks Justice v. Just Mayo," Wall

Street Journal, November 11, 2014, B3; Stephanie Strom, "Hellman's Maker Sues Company Over Its Mayo Substitute," New York Times, November 11, 2014, B2; Drew Harwell, "'Food giant starts war over meaning of mayo,"' Washington Post, November 11, 2014, A18.

2221 Code of Federal Regulations Section 169.140.

${ }^{23}$ Conopco, Inc. V. Hampton Creek, Inc., Notice of Voluntary Dismissal, December 18, 2014. See also Unilever United States, Inc., Press Release, "Unilever Withdraws Lawsuit Against Hampton Creek,"'Forbes.com, December 18, 2014 and Ryan Mac, "Unilever Drops Mayo Lawsuit Against EggReplacing Startup Hampton Creek,"' December 18, 2014 <wW. forbes.com/sites/ryanmac/2014/12/18/unilever>. ${ }^{24}$ Stephanie Strom, "Unilever, Suing Rival for Use of 'Mayo,' Changes Own Website,'' New York Times, November 17, 2014, B6. See also Michele Simon, “Mayogate: Unilever Doctoring Customer Reviews,"' November 16, 2014 <wWW . eatdrinkpolitics . com/2014/11/16/mayogate-unilever doctoring-customer-reviews>.

25 Josh Tetrick quoted in Strom, "Unilever, Suing Rival." ${ }^{26}$ Schwartz, "Inside the Company." 
${ }^{27}$ Nick Wingfield, "Hampton Creek Slashes Staff,"' New York

Times, March 23, 2015, B4. 
5. Plant-Based Chicken and Beef Substitutes: Beyond Meat

For years companies have tried to develop alternatives to meat, which people increasingly avoid for health, environmental, food safety, and animal welfare reasons. The challenge is to find substitutes with comparable taste and texture.

Embarking on a quest to revolutionize eating with plant-based proteins that are better for consumers, animals, and the planet, Beyond Meat, analyzed in this chapter, seeks to produce and market a new kind of meat for the world. The firm strives to compete in the multibillion dollar beef and chicken industry and tackle a range of problems developed in Chapter 2, including improving human health and wellness, positively impacting the environment, addressing global resource constraints, and improving animal welfare. Rising to the difficult challenge, it provides consumers with hyper-realistic plant-based meat substitutes that provide the taste, texture, and nutritional benefits of chicken and beef.

Failed Soy Protein Substitutes 
Mock meats from leading food processor companies, such as Kellogg Co. and Kraft Foods Group, Inc. are found in supermarket refrigerators and freezers. They are branded as Morningstar Farms Chik'n Nuggets, Turtle Island Foods Tofurky, Fried's Soyrizo, Boca's All American Flame Grilled Meatless Burgers, and Nate's Classic Flavor Meatless Meatballs. These soy-based products use: pressed tofu, made by curdling fresh, hot soymilk with a coagulant; tempeh, a fermented soy product pressed into a cake; or textured soy protein, made from textured soy flour, textured soy protein, and spun soy fiber. ${ }^{1}$

It is difficult, if not nearly impossible, to replicate the mixture of protein and fat found in meat. Heat from cooking alters the protein thereby creating meat's distinctive texture. Fat in meat provides flavor. Soy protein, however, is fat free. These substitutes lack the texture--the bit, chew, and juiciness of real meat. Not fibrous, they generally exhibit a spongy structure. Not resembling meat-like muscle food, they typically are also more expensive than real chicken or beef and thus, for several reasons, have not achieved a high degree of market 
penetration. In addition, it is harder and harder to obtain soy from non-genetically modified organisms.

Beyond Meat

Founded in 2009, by Ethan Brown and Brent Taylor, Beyond Meat provides consumers with plant-based protein foods that remove animals from the production of chicken or beef without sacrificing taste, chew, or satisfaction. For example, its plant-based, chicken-free products look and taste like chicken. With a chewy, fibrous texture, they feel like chicken on taking a bite. They have a plumpness, what is called "mouthfeel," a kind of fattiness."

Beyond Meat: Its Origins

After a successful career in the clean energy sector, specifically, the burgeoning field of fuel cells with Ballard Power Systems, a Canadian energy company, Brown realized that energy could only meet part of the climate change problem, at least as he saw it. With livestock generating so many greenhouse gas emissions, a basic question nagged him, why "continue to raise and eat animals in such staggering numbers if a delicious and 
perfect plant-based replication of meat existed?' ${ }^{\prime 3}$ As a vegan, also concerned about animal welfare, he searched for a technology that could answer his question, taking plantbased proteins and realigning them to mimic the appearance and sensory experience of animal chicken and beef.

Without leaving his corporate position, Brown invested in several vegetarian restaurants specializing in mock meat sandwiches and salads made with soy-based tofu and seitan, a wheat gluten. Despite growing sales at these restaurants, he did not think that any of the items sold were good enough to eat without heavy seasoning or sauces.

In 2006, Brown began thinking seriously about creating animal protein with plants. Poring over the scientific literature, he discovered the work of Fu-hung Hsieh and his colleague, Harold Huff, a professor of food science and biological engineering and a senior research specialist, respectively, at the University of Missouri-Columbia.

Hsieh had focused on meat analogs, indistinguishable fakes, after writing his doctoral thesis on textured vegetable protein in the 1970s. He spent seven years at Quaker Oats, developing a patented technology to keep raisins in granola soft and moist. Because of his concern 
about the global food supply, Hsieh returned to academia. With funding from the soy industry and the U.S. Department of Agriculture, Hsieh teamed up with Huff in an effort to produce a chicken-like product from soybeans.

For more than a decade, Hsieh and Huff toiled to devise the basic technique that Beyond Meat uses to produce its chicken- and beef-like products. ${ }^{4}$ In brief, the duo developed a high-moisture extrusion process, alternating high heat with high pressure, to reorganize plant proteins into a more animal-like alignment. Pressed through a large stainless steel extruder, the manipulated proteins ooze out as a kind of sludge.

After Brown sought out Hsieh and Huff and began a collaboration with them, the trio teamed up and entered into an informal agreement to try to turn plant-based chicken into a business.

With the production process solved, Brown approached the product from a marketing angle. To generate a distribution outlet, Brown met with a Whole Foods Market representative to pitch the chain on using the chicken-like product. Louise Liu, who oversaw Whole Foods product development in the Mid-Atlantic region, advised him she was 
looking for an ingredient that could substitute for shredded chicken in the company's prepared foods.

Realizing he had a product with wide appeal, Beyond Meat was born.

Beyond Meat: Its Management and Licensing

Brown, the firm's co-founder along with Brent Taylor, a former Kleiner Perkins employee, serves as its chief executive officer.

Beyond Meat licensed the two researchers' veggie chicken process. Under a 2010 licensing agreement, the University of Missouri-Columbia and the two scientists/investors receive royalties based on Beyond Meat's revenues. The university also owns a small equity stake in the firm.

Beyond Meat's Mission and Vision

Beyond Meat has a lofty corporate mission and vision. Its mission centers on creating mass market solutions perfecting and replacing animal protein with plant protein. ${ }^{5}$ As its vision, the company wants to reduce the world's consumption of animal meat by 25 percent by $2020 .{ }^{6}$ Beyond 
Meat's factory in Columbia, Missouri can produce the equivalent of about 18 million chickens each year. Today, about 8.6 billion chickens are raised and slaughtered in the United States. Thus, Beyond Meat's 25/20 Vision appears unrealistic, absent other major entrants into the substitute animal meat arena.

Beyond Meat's Products

Beyond Meat's first product line, Chicken-Free Strips, embodies crafting plant-based proteins that replicate the sensory experiences of meat. Reflecting a blend of non-GMO (genetically modified organisms) soy and pea protein, a 3 ounce serving of Chicken-Free Strips delivers 20 grams of protein, but only 120 calories and 6 grams of carbohydrates. The strips are free of trans and saturated fats, cholesterol, dairy, egg, hormones, genetically modified organisms, antibiotics, meat, and gluten. ${ }^{7}$

The strips are made from: soy protein isolate, a protein isolated from soybean meal which has been dehulled and defatted; pea protein isolate; soy fiber; pea fiber; carrot fiber; and amaranth, a gluten-free grain. other ingredients include dipotassium phosphate, a common source 
of potassium, titanium dioxide, a naturally occurring mineral that helps the product look like chicken, and a vegan, plant-based chicken flavoring, consisting of maltodextrin, yeast extract, salt, natural flavoring, and sunflower oil.

Once measured, the dry ingredients are mixed with water, white vinegar, and expeller-pressed canola oil, which is free of saturated fat, to form a liquid paste. The mixers empty the resulting concoction into a cookerextruder, a stainless steel machine, which heats and kneads the slurry under pressure to achieve the desired consistency. The product is then forced through specially made dies, which shape and cut the product. Four-inch long chicken-like strips emerge from the extruder, with the flavor and texture of the real thing.

The pre-cooked, pre-seasoned strips now come in three varieties: Southwest Style Strips, Grilled Strips, and Lightly Seasoned Strips.

Beyond Meat has also developed several beef-like products. Using pea, not soy, protein, its Beefy crumbles and Feisty Crumbles substitute for ground beef. Consumers, food companies, restaurants, and school districts, among 
others, can work these beef crumbles into tacos, lasagna, and sloppy joes.

In 2014, the firm unleashed The Beast Burger, a burger patty, and Beastly Sliders, both made from pea protein. They feature more iron and protein than beef, more calcium than milk, and more omegas than salmon. They are soy, gluten, and GMO free.

However, making fake steak is harder than making chicken strips or beef burgers. For example, people expect steak to look a bit red, from blood. More generally, it is hard to match the texture.

Financing Beyond Meat

With Beyond Meat's chicken-strips indistinguishable from the real thing, the firm experienced little difficulty in raising capital. ${ }^{8}$ Kleiner Perkins Canfield \& Byers, one of the largest and most established venture capital firms, provided the initial funding, in a first-round, for Beyond Meat in 2011. The cash came in two tiers: the first, a proof-of-concept stage that allowed Brown to build a small production line in a former hospital and the second, when Whole Foods bought more of the chicken-like product. 
The second funding round included Kleiner Perkins, Obvious Corporation, the tech incubator of Twitter cofounders, Christopher Isaac (Biz) Stone and Evan Williams, a former Twitter vice president, Jason Goldman, and a few others. Stone and Williams ultimately joined Beyond Meat's board of directors.

A third funding round included Bill Gates, Morgan Creek Capital, Closed Loop Capital, and Seth Goldman, the co-founder of Honest Tea.

New investors in a July 2014 Series D financing round included DNS Capital, representing the business interests of Jean (Gigi) Pritzker (Pucker) and Michael Pucker, Taiwan's Tsai family, through its family office, WTT Investment, and S2G. All of the existing investors also participated in this round.

The 2014 round enabled Beyond Meat to fund even greater innovative efforts to re-create meat from plants. The round also help the company expand consumer awareness and increase the company's manufacturing facility's capacity to meet the growing demand for its products.

Beyond Meat's Distribution 
Beginning in 2012, Beyond Meat began providing its chicken-like strip product to Whole Foods Market for use in its prepared food sections, initially in the California Bay Area. Subsequently, in the spring of 2013, the firm made its chicken-like strips available to consumers in supermarkets, including not only whole Foods, but also Publix, Safeway, Vons, and Ralphs, among others, throughout the United States. ${ }^{9}$ With the product available in these supermarkets' refrigerator cases with many other chicken substitutes, people can now purchase Beyond Meat's chickenstrips and heat it for themselves at home. Consumers can also buy the strips online through VeganEssentials.com and Veganstore.com.

Beginning in May 2013, Tropical Smoothie Café, a chain of more than 300 (336) stores that sells sandwiches and salads as well as smoothies, offered Beyond Meat's chickenlike product as an alternative to real chicken it its sandwiches and salads. ${ }^{10}$ In July 2013 , the product became a permanent fixture on the chain's menu.

Awards Received 
In 2014, Fast Company magazine named Beyond Meat as one of the world's most innovative companies in the food category. ${ }^{11}$ It was included in the magazine's fifty most innovative firms in the world. Previously, PETA (People for the Ethical Treatment of Animals) named the firm as its company of the year in 2013.

Looking To The Future

Today, the suggested retail price for a 12-ounce package of Beyond Meat's chicken strips is less than a ready-to-eat equivalent, such as Perdue Short Cuts. However, big, vertically-integrated U.S. chicken producers, such as Tyson Foods and Perdue Farms, grow and process chickens for less than it currently costs Beyond Meat to produce its strips.

In the future, because it uses less feed, Beyond Meat may be able to compete with the leading U.S. chicken producers in a sustainable, profitable, scalable manner. A pound of its chicken-like strips needs only 1.1 pound of ingredients and two liters of water. Broilers require 7.5 pounds of dry feed and 30 liters of water to yield one pound of cooked, boneless chicken. ${ }^{12}$ Feed costs account for 
some 35 percent of the costs of chicken. ${ }^{13}$ If costs of feed, as well as energy and fertilizer rise over time, Beyond Meat will likely obtain a competitive cost advantage over traditional chicken producers and their products. To scale the business, Brown must figure out how to market Beyond Meat's processed, not "'natural," products and to whom. In addition to the quality of its products and their health, environmental, food safety, and animal welfare benefits, purchasers must derive a "great experience." At present, the company targets healthconscious carnivores, who want to reduce their meat consumption, not just vegans or vegetarians. It hopes that supermarkets will carry its chicken and beef products in the respective meat aisles, not in the plant-based protein section.

However, its chicken-like strips currently are frozen at the factory. As a result, they suffer from many of the texture issues that frozen meat faces when thawed, namely, graininess and chewiness. At present, it is unclear whether Brown can ship the product refrigerated rather than frozen . 
Also, for purists, soy in its chicken-like strips represents a possible contentious ingredient because of possible health risks and a negative connection to large farm, industrial agriculture. Beyond an allergy or food intolerance to soy, women with current or past breast cancer may face potential tumor growth when taking soy products. ${ }^{14}$

At the end of the day, Brown believes, however, that the public will accept Beyond Meat's innovations as they have adapted to past technology revolutions. "Once, we had the horse-drawn carriage, and then we had the horseless carriage, and then we had the automobile," Brown stated. He continued, "I'm firmly convinced we're going to go from beef and chicken products that are animal in origin to those made from plants--and at some point in the future you'll walk down the aisle of the supermarket and ask for beef and chicken, and like the automobile has no relationship to the horse, what you get will have nothing to do with animals. ${ }^{\prime \prime 15}$

\footnotetext{
${ }^{1}$ University of California San Francisco Medical Center, A Guide to Foods Rich in Soy
} 
<wWw.ucsfhealth.org/education/a_guide_to_foods_rich_in_soy> (December 12, 2014).

2 I have drawn on Jonathan Ringen, "Carnivores may never know the difference: Beyond Meat's Quest To Change The World, One Protein Fiber At A Time,"' Fast Company 189 (October 2014): 106-110, 159; Tom Foster, "The Meat Lab: Can Engineered Beef, Chicken, and Pork Save The World?,'" Popular Science 283:5 (November 2013): 56-63, 78; David Pierson, "Substitute-meat makers' art imitates life," Los Angeles Times, November 9, 2013 <ww. latimes.com/business/la-fi-meat-20131109-story.html>; Marc Gunther, "The Bill Gates-backed company that's reinvented meat,"' Fortune, October 3, 2013 $<w W W$. for tune.com/2013/10/03/the-bill-gates-backed-companythats-reinventing-meat>; Alton Brown, "Tastes Lake Chicken: How One Company Created A Plausible Substitute For Meat That Has The Texture of Real Flesh," Wired, September $2013<$ <Ww. wired.com/2013/09/fakemeat>.

${ }^{3}$ Ethan Brown quoted in Beyond Meat, Company Backgrounder, n.d. See also Beyond Meat: "About: Meet the Future" <wWw. beyondmeat. com/about> (September 3, 2014). 
${ }^{4}$ In Hsieh and Huff's most-cited academic article, S. Lin, H.E. Huff, F. Hsieh, "Extrusion Process Parameters, Sensory Characteristics, and Structural Properties of a High Moisture Soy Protein Meat Analog,"' Journal of Food Science 67:3 (April 2002): 1066-1072, they set forth their technology, involving ingredients, moisture, heat, and extrusion, to create a product similar to animal meat. For background on the Hsieh-Huff collaboration see John Cloud, "Creating Chicken Without the Egg," TIME 175:23 (June 14, 2010): $97-98$.

5 Beyond Meat, "About: Our Mission" <WWW. beyondmeat.com/about> (September 3, 2014).

${ }^{6}$ Beyond Meat, "About: Our 25/20 Vision" <wWW. beyondmeat.com/about/25-20-vision> (September 3, $2014)$.

7 Beyond Meat, "Products"' <wWW. beyondmeat.com/products $>$ (November 7, 2014) and "FAQ" <WWW. beyondmeat.com/faq> (November 7, 2014). For a review of quality of Beyond Meat's products see Corby Kummer, "The Problem with Fake Meat,'" MIT Technology Review.com, March 31, 2015; Interview of Corby Kummer, "The Fake Meat Industry's Quest To Make Faux Taste Real,'" National Public Radio, April 2, 
2015<www.npr.org/2015/04/02/397097036>; James Joiner, “'The Veggie Burgers With Meaty Ambition,"' DailyBeast.com, January 15, 2015

$<$ wW. thedailybeast. com/articles/2015/01/15/the-veggieburgers-with-meaty-ambition-html>.

${ }^{8}$ Beyond Meat, Press Release, "Beyond Meat Completes Largest Financing Round to Date,"' July 28, 2014. See also Ringer, "Tastier, Healthier."

${ }^{9}$ Beyond Meat, Press Release, “Beyond Meat ${ }^{\mathrm{TM}}$ Launches First Meat-Free and Gluten Free Chicken-Free Strips,"' April 2013. In 2014, several Whole Foods Markets accidentally sold mislabeled chicken salad with the firm's chicken-like strips, not real poultry, leading to a recall of the chicken salads. Prior to correcting the error, consumers had eaten the "fake" chicken without noticing any difference. Stephanie Strom, "Fake Meats, Finally, Taste Like Chicken,"' New York Times, April 3, 2014, B1. ${ }^{10}$ Beyond Meat, Press Release, “Meatless Monday Isn't Just For Monday Anymore,"' May 20, 2013.

11 Jane Black, "'Rebuilding Big Food," Fast Company 183 (March 2014): 132-136, at 136. See generally Fast Company, 
"The World's 50 Most Innovative Companies" 183 (March 2014): 74-148 .

12 Foster, "The Meat Lab," 56.

${ }^{13}$ Gunther, "'Bill-Gates-backed."'

${ }^{14}$ See, e.g., Mário L. DeLemos, "Effects of Soy

Phytoestrogens Genistein and Daidzein on Breast Cancer

Growth," Annals of Pharmacotherapy 35:9 (September 2001):

1118-1121 and Mark Messina, Worta McCaskill-Stevens,

Johanna W. Lampe, "Address the Soy and Breast Cancer

Relationship: Review, Commentary, and Workshop

Proceedings,"' Journal of the National Cancer Institute

98:18 (September 20, 2006): 1275-1284. But see Jia-Yi Dong and Li-Qiang Qin, "Soy isoflavones consumption and risk of breast cancer incidence or recurrence: a meta-analysis of prospective studies, "'Breast Cancer Research and Treatment 125:2 (January 2011): 315-323. See also David Schardt, "Soy Oh Soy!" Nutrition Action Health Letter 41:7 (September 2014): 9-11.

${ }^{15}$ Ethan Brown quoted in Farhed Manjoo, "Fake So Good It Will Freak You Out,'" Slate, July 26, 2012 $<W W$. slate.com/articles/technology/technology/2012/07/beyon 
d-meat-fake-chicken-that-tastes-so-real-it-will-freak-youout.html>. 
6. Plant-Based Beef Substitutes: Impossible Foods

The chapter examines the efforts of Patrick Brown to go beyond cheeses, examined in chapter 3, and manipulate plant material to create a meat facsimile, with the right taste, mouthfeel, and texture. With his proof-of-concept, which mimics meat from vegetable sources, Brown attracted one of the largest amounts of venture capital funding of any of the firms discussed in this book, apart from Hampton Creek. Despite his audacious efforts, little is publicly known about Brown's company, Impossible Foods.

Brown, a vegan, sees a much bigger market for plantbased animal product substitutes than just the Kite Hill cheeses sold by Lyrical Foods. Motivated mainly by environmental concerns and a desire to create more sustainable food sources, he wants to put a significant dent in our hunger for beef and thus reduce, and if not eventually eliminate, the animal farming industry. ${ }^{1}$

After two years of background research, Brown's quest led him to organize Impossible Foods, Inc. in 2011. The company has as its mission "to give people the great taste and nutritional benefits of foods that come from animals without the negative health and environmental impact."'2 
The Science Behind Plant-Based Beef

In his quest to develop a plant-based meat, Brown, given his scientific background, sought to understand the molecular reasons why beef tastes like beef. ${ }^{3}$ To replicate the taste of meat, he needed to understand and create plant "blood."

Heme, a molecule in hemoglobin and myoglobin, two key proteins, found not only in cows' blood, among other animals, but also in plants, makes blood red. ${ }^{4}$ Brown found that heme is responsible for beef's distinctive color. When exposed to amino acids and sugars, it unlocks flavors. As a major carrier of iron, its presence likely also gives cooked beef its distinctive taste.

To solve the texture riddle, Brown and his team identified those plant compounds requisite to creating fat, connective tissue, and muscle. These compounds give the "meat" the consistency of real beef. Because researchers can control the placement of fat in a piece of meat, the uniform distribution of fat yields perfectly marbled beef. 
The result: as his proof-of-concept Brown created a hamburger that looks and smells like a cooked ground beef burger. Although its taste and texture are not perfect, at present, it has the appropriate mouthfeel. ${ }^{5}$ Its protein content is higher than a conventional burger. It is free of antibiotics, hormones, and cholesterol.

Financing Impossible Foods

Based on Brown's research and the quality of Impossible Foods' meat-like product, thus far developed, in 2014 the company gained some $\$ 75$ million in capital from Khosla Ventures, Horizon Ventures, Google Ventures, the independent venture capital arm of Google Inc., which provides funding for technology companies, and Bill Gates. ${ }^{6}$ Most of the funds went into creating the company's manufacturing facility.

Looking To The Future

Even with its proof-of-concept, Impossible Foods faces a major hurdle. To market its beef product, the firm must substantially reduce the $\$ 20$ cost of producing a small patty. It is unclear whether the company can devise 
cheaper manufacturing processes and decrease the cost of its raw materials, even if its scale increases. At present, Brown's burger requires large quantities of five plant species. However, Brown's quest for excellent tasting, healthy "'meat," which is best for the planet, and affordable, continues.

${ }^{1}$ Matthew Herper, "Drop That Burger," Forbes.com, November 12, $2009<w W W$. forbes.com/forbes/2009/1130/thought-leaders mcdonalds-global-warming-drop-that-burger-html>. 2 Impossible Foods, "About" <wW. impossiblefoods.com/about> (October 13, 2014). ${ }^{3}$ Evelyn M. Rusli, “The Secret of These New Veggie Burgers: Plant Blood,"' Wall Street Journal, October 8, 2014, B1. ${ }^{4}$ Heme may, however, promote the formation of potentially carcinogenic compounds. As to the link between red meat intake and cancer see World Cancer Research Fund and American Institute for Cancer Research, Food, Nutrition, Physical Activity, The Prevention of Cancer: a Global Perspective, 2007, 120-122. But compare Dominik D. Alexander et al., Red Meat and Processed Meat Consumption and Cancer: A Technical Summary of The Epidemiologic 
Evidence, National Cattleman's Beef Association, January 2010, Sections 10, pp. $1-5$ and 11, p. 7.

${ }^{5}$ For one journalist's review of Impossible Foods' burger's taste and texture see Evelyn M. Rusli, "Not Your Typical Veggie Burger: What Impossible Foods' Creation Tastes Like," Wall Street Journal, October 8, 2014, B6.

${ }^{6}$ Rusli, "Secret." 
7. Bioengineered Meat and Leather: Modern Meadow

Through stem cells, cell culture, and tissue engineering, academic scientific researchers have created lab-grown meat by biopsying and isolating the desired cells from living animals, growing these cells, and producing a beef surrogate made of the same real meat is composed of. They grow this test-tube engineered meat in vitro, that is, outside of an animal's body.

One firm, Modern Meadow, profiled in this chapter, plans to apply biofabrication technology first to create leather from animal skin cells. With the meat we eat consisting of muscle tissue from animals, such as cows, working with molecular technology experts, the company ultimately hopes to create cultured meats from muscle cells.

\section{Biofabrication Meat Academic Pioneers}

In 2013, a team of Dutch researchers led by Mark J. Post, M.D., Ph.D., successfully unveiled the first labgrown burger from cow stem cells.

Post, a professor in the physiology department at Maastricht University in the Netherlands, a vascular 
biologist and a surgeon, with a doctorate in pulmonary pharmacology, ${ }^{1}$ had shifted part of his research from biomedicine, more specifically, creating arteries to replace and repair those in diseased human hearts, to develop lab-grown meat.

In August 2013, Post demonstrated the world's first lab-grown hamburger for the press. ${ }^{2}$ At a news conference, which was broadcast live on the web, a food writer and a food scientist ate the five-ounce burger that was grown from stem calls taken from two cows. One taster positively indicated, "The mouthfeel is like meat. I miss the fat, there's a leanness to it, but the general bite feels like a hamburger. ${ }^{\prime 3}$ The other was more guarded in his assessment.

To produce the cultured beef burger, Post's team first biopsied adult stem cells from a donor cow. ${ }^{4}$ After extracting and isolating the muscle stem cells, the team incubated these cells in a growth mixture, consisting of amino acids, sugars, minerals, and fetal bovine serum, to supply the nutrients blood would ordinarily provide. The last ingredient, a clear liquid separated from unborn calf embryos' clotted blood, represented the by-product of the slaughter of pregnant cattle. As the muscle cells 
multiplied, they grew together, forming muscle tissue. To facilitate the multiplying and fusing, researchers attached muscle cells to specially prepared cylindrical scaffolds and used tension to simulate muscle maturation.

The August 2013 hamburger that Post presented and had cooked and sampled used some 20,000 muscle strips. To ensure that the nutrient-rich growth medium reached all muscle cells, the team produced the lab-grown muscle tissue in very small pieces. In making the burger, Post also added beet juice, caramel, and saffron to improve its color and flavor, and breadcrumbs and egg power to obtain a texture more similar to ground beef.

The test demonstrated the technology's proof-ofconcept. Establishing the technical feasibility of using tissue engineering to create cultured beef was, however, exceedingly expensive. It cost about $\$ 325,000$, paid for by Sergey Brin, Google's co-founder. Because of its price tag, this product is not consumer-ready.

In addition to the need to generally reduce costs and increase efficiency, ${ }^{5}$ to become commercially viable and meet scale up demands, Post must develop a cheap, effective substitute for expensive fetal bovine serum, the growth 
promoting blood-derived product. Besides being expensive, some $\$ 500$ for 500 milliliters and not animal friendly, different batches of serum-based media have variable impacts on cell growth, which renders it unacceptable for commercial uses.

If a business wants to exclude living farm animals from the biofabrication process, apart from extracting cells, lab-grown meat would need a non-animal-based growth medium. A plant-based growth medium, such as algae, should be less expensive than fetal bovine serum; however, it is unclear whether a plant-based medium would cause allergic reactions in some consumers.

Post also sees the need to work on the cultured meat's fat content and its protein composition. ${ }^{6}$ As noted, Post confined the technology to small pieces of muscle tissue. Post's lab-grown meat lacks the blood vessels needed to deliver oxygen and nutrients into the tissue to keep it alive and make thick muscle tissue for certain meat cuts, such as steak. It is uncertain whether researchers can figure out a way to somehow synthesize something like blood vessels so as to nourish cells at the center of the muscle tissue as it grows thicker. 
In short, the product of Post's methodology is too expensive at present. Even if costs fall substantially, the technology may be too complex to be commercially viable.

\section{Modern Meadow}

Modern Meadow develops cultured leather and meat from animal stem cells. It uses biofabrication, a tissueengineering technology to grow leather from skin cells and meat from muscle cells.

Modern Meadow: Its Origins

A father-son team, Gabor and Andras Forgacs, founded Modern Meadow. Gabor Forgacs, Ph.D., a theoretical physicist who turned to developmental biology, holds an endowed chain and heads the University of MissouriColumbia's biophysics laboratory and serves as the executive and scientific director of Clarkson University's Innovation Center. 
The father's scientific team invented and the son helped commercialize bioprinting, a technology facilitating building tissues based on 3D computer-controlled cell delivery. ${ }^{7}$ In 2007, they co-founded Organovo, now a publicly-held regenerative medicine company, which applies bioprinting technology to medical applications. ${ }^{8}$ The company bioengineers human tissues for use by pharmaceutical companies in drug development and testing, among other medical applications. As an elusive goal, Organovo's human tissues could ultimately serve as replacement organs, such as a kidney, for patients needing a transplant. If bioprinted organs were made from patients' own cells, they would not be subject to rejection by immune systems. These organs could also be produced on demand.

After their success with human tissues, the duo started getting a question: If you can grow human body components, can you grow animal products, such as meat and leather? However, with a medical focus, Organovo's technology centered on engineering high-fidelity human tissues. To take bioengineering technology beyond regenerative medicine, the father-son team founded a new 
company, Modern Meadow, after Organovo brought in a new management team in 2011 and formulated plans to go public.

Modern Meadow: Its Founding And Focus On Leather

In September 2011, Andras Forgacs co-founded Modern Meadow with his father, Gabor, and two of Gabor's university colleagues, Françoise Marga and Karoly Jakab. In January 2012, Andras became its chief executive officer, with Gabor serving as its chief scientific officer. The firm plans to use Gabor's research to create leather goods and cultured meat for the consumer market. ${ }^{9}$

A big market exists for novel consumer biomaterials, such as leather. For example, a $\$ 63$ billion annual global market exists for leather products. ${ }^{10}$

The father-son duo began to reimagine cultured leather to be used to make consumer goods, such as shoes, apparel, handbags, and luggage. Growing leather involves one type of cell, the basic unit of life, to make skin, and is largely two-dimensional. Leather, even meat, is simpler to produce than functioning human parts, Organovo's focus. No need exists to be as exacting or worry about compatibility. 
Thus, through biofabrication, Gabor's technology, cells can grow biological products, such as leather.

Modern Meadow's Technology

The biofabrication process for leather is straightforward, with skin cells having a simpler molecular structure than muscle cells for meat. Through a biopsy, Modern Meadow begins by taking stem cells from an adult donor animal, such as a cow which leads a normal life. For leather, it then isolates the skin cells and multiplies them in a bioreactor's cell culture, using fetal bovine serum, as noted, a fluid derived from calves' embryos. After centrifuging the mixture to eliminate the growth medium from the skin cells, it lumps the cells together to create aggregated spheres of cells. The firm coaxes the cells to produce collagen, material between the cells, which serves as a natural connective tissue. Collagen gives the cells structural support as it would do in an animal. In leather, collagen serves as the product's main building block. The company then takes the skin cells and the collagen, and spreads them out to form sheets, layering the thin sheets on top of one another to form thicker 
sheets in a process called bioassembly. The sheets are then left to mature and thicken. Dispensing with chemical intensive, early tanning steps designed to remove animal hair and flesh, through a shorter, less toxic chemical tanning process, the firm creates real leather from the multilayered skin cells.

The leather end product of the biofabrication process has all the characteristics of genuine leather. It is made from the same cells. Furthermore, there is no hair to remove or any waste from irregular natural hides. The cultured leather is free from imperfections, such as scars or damage from insects or barbed wire. The firm can finetune its leather for desirable qualities, such as thickness, softness, durability, or elasticity, so as to improve on it.

Marketing Modern Meadow's Leather

From a marketing standpoint, leather represents a "gateway product" on which to build Modern Meadow and the biofabrication industry. According to Andras Forgacs, "It [leather] is less...polarizing for consumers and regulators. Until biofabrication is better understood, it is clear 
that, initially at least, more people would be willing to wear novel materials than would be willing to eat novel foods, no matter how delicious. ${ }^{\prime 11}$ He also noted that anecdotally only about " 40 percent of people would be willing to try cultured meat. There's much less controversy about using leather that doesn't involve killing animals. ${ }^{\prime 12}$ Beyond public perceptions, lab-grown leather would not require approval by the U.S. Food and Drug Administration (FDA).

The U.S. Department of Agriculture is responsible for the safety of meat, poultry, and processed egg products, with the FDA responsible for all other foods. The FDA's treatment of cloned animals provides insight into how it might handle in vitro meat. In 2008, the FDA announced that humans could safely consume meat from cloned animals, specifically cattle, pigs, and goats, any products derived from such animals, and their offspring. ${ }^{13}$ In reaching this conclusion, the FDA considered various factors, such as the use of clones primarily for breeding and the nature of these clones compared to genetically-engineered animals. The U.S. Department of Agriculture regulates the safety of meat in the United States, focusing on preslaughter 
inspections of animals, including requiring sterile and sanitary conditions for any surface or tool coming in contact with meat, the use of safe cleaning products to ensure sanitary conditions, and a standard of cleanliness for those working with meat. ${ }^{14}$ In short, the Agriculture Department, which strives to ensure that meat products do not become adultered as a result of unsanitary processing and handling, would likely assume primary responsibility in ensuring the safety of in vitro meat.

Given the absence of regulatory approval for leather, Modern Meadow hopes to have full-scale leather production facility up and running in five years (2012 to 2017). The regulatory process for in vitro meat could take upwards of ten years (2012 to 2022).

Initially, the company will introduce its leather at the high-end of the leather price spectrum, some $\$ 1,000$ per square meter (or about $\$ 100$ per square foot). When production scales up, its leather will become more affordable, at least that is the firm's not unreasonable expectation.

Financing Modern Meadow 
Building on the practicality of its biofabrication technology, Modern Meadow obtained various grants and received funds from investors, including high profile venture capitalists. In 2012, the firm received a $\$ 92,000$ $(\$ 92,488)$ Small Business Innovation Research (SBIR) Phase One grant from the U.S. Department of Agriculture for its bioengineered meat. ${ }^{15}$ The next year, it received a \$150, 000 $(\$ 149,994)$ U.S. National Science Foundation SBIR Phase One grant for its Tissue Engineered Sustainable Leather ${ }^{16}$ Non-governmental grants also funded the firm. In August 2012, through Breakout Labs, Peter Thiel, a prominent venture capitalist, PayPal co-founder, and an early Facebook investor, backed Modern Meadow with a $\$ 350,000$ grant. ${ }^{17}$ Breakout Labs serves as the Thiel Foundation's initiative focused on assisting what it regards as breakthrough science and technology companies. It gives grants to early stage research projects deemed unsuitable for traditional funding sources because of their radical nature or too speculative to interest venture capitalists. With the help from these funds, Andras Forgacs set up an office at the Singularity University Labs Idea Center on NASA's Silicon Valley research park campus. 
Previously in 2012, Singularity University, a technology advancement and education organization, included Modern Meadow in its inaugural synthetic biology accelerator program, SynBio Startup Launchpad. In addition to a $\$ 60,000$ grant, Modern Meadow founders underwent four months of comprehensive, customized mentoring and education to help bring their ideas to market. ${ }^{18}$

After obtaining nearly $\$ 1.5(\$ 1.4)$ million in

investments from angel investors and seed venture capital funds, including Sequoia Capital, Artis Ventures, and Iconiq Capital, in June 2014, the company raised $\$ 10$ million in a Series A convertible preferred stock funding round led by Horizons Ventures. ${ }^{19}$ The firm used the funds to accelerate its research and development and open an expanded research headquarters in Brooklyn, New York.

\section{Award Received}

In 2013, Entrepreneur magazine named Modern Meadow as one of its 100 brilliant companies. Specifically, the magazine designated the firm as "leading the future of farming. ${ }^{\prime \prime 20}$ 
Looking To The Future

Modern Meadow appears wise to focus its efforts initially on leather, not meat. Beyond the regulatory uncertainties and delays with respect to biofabricated meat, a challenge exists in persuading consumers to buy cultured meat. Unlike Brown's Impossible Foods' beef, at present Modern Meadow's meat lacks blood and fat content. Apart from palatability questions, including appearance, taste, texture, and aroma, the company may face public opposition to lab-made meat. Simply put: it's the "yuck" factor. ${ }^{21}$

However, people daily eat cultured food products, such as cheese and yogurt. Also, if the price of real meat rises because the supply cannot match the growing demand, necessity may cause the opposition to decline. The firm may also sell "supermeats," which would be enhanced with items, such as omega-3, not found in the real thing. Even overcoming the consumer acceptance hurdle, Modern Meadow faces three further obstacles in its efforts to commercialize bioengineered meat production. First, 
despite the grants and investments the firm has obtained to date, some estimates indicate that the commercialization of cultured meat production by one firm may require an investment of upwards of $\$ 160$ million. ${ }^{22}$

Second, to reduce costs and gain uniformity, Modern Meadow would want to grow muscle cells and its meat without the aid of an animal-derived liquid culture medium, such as fetal bovine serum.

Third, producing biofabricated meat on a large, efficient scale raises additional questions. Growing meat in giant bioreactors, expensive to design, build, and maintain, may raise energy issues. However, only small amounts of electricity, perhaps from solar panels, may be required to regulate bioreactors' temperatures.

Cultured meat production requires some type of exercise to stimulate muscle growth in what will become meat. It is uncertain whether just a minor electric current can mimic the effects of natural bovine movements. ${ }^{23}$ Thus, exercising muscle fibers with electricity may not be energy efficient. However, despite these cost considerations, cultured meat will require less water, land, and energy inputs, per pound, than traditional meat. 
${ }^{1}$ For background on Mark J. Post see Carole Cadwalladr, "Laboratory-grown beef: meat without the murder, but would you eat it?'" Guardian (London), July 13, 2014 <WWW. theguardian. com/science/2014/jul/13/laboratory-grownbeef-meat-without-murder-hunger-climate-change> and Henry Fountain, "Building a \$325, 000 Burger,"' New York Times, May 12, 2013, D1.

2 Henry Fountain, "Frying Up a Lab-Grown Hamburger," New York Times, August 6, 2013, D5; Shirley S. Wang, "Scientists Cook Up Lab-Grown Beef," Wall Street Journal, August 6, 2013, A9; Economist, "A quarter-million pounder and fries,"' 408:8848 (August 10, 2013): 9; Alok Jha, "Synthetic meat: how the world's costliest burger made it on to the plate,"' Guardian (London), August 5, 2013 $<$ wW. theguardian.com/science/2013/aug/05/synthetic-meatburger-stem-cells>; BBC News: Science \& Environment, "World's first lab-grown burger is eaten in London," August 5, 2013 <wW.bbc.com/news/science-environment2357143>; Melissa Hogenboom, "What does a stem cell burger taste like?,"' BBC News: Science \& Environment; August 5, 2013 <wWw. bbc.com/news/science-environment-23529841>. 
${ }^{3}$ Josh Schonwald quoted in Jha, "Synthetic meat." This same taster also said that the meat tasted "like an animal-protein cake.'" Josh Schonwald quoted in Fountain, “'Frying Up."'

${ }^{4}$ For an analysis of the technology using stem cells, cell culture, and tissue engineering see Mark J. Post, Helen E. Breewood, Anon L. van Essen, "Cultured beef: current status and challenges," Food Science and Technology Journal, January 3, 2013 <wWw.fstjournal.org/features/271/cultured-beef>; Mark J. Post, "Cultured meat from stem cells: Challenges and prospects,"' Meat Science 92:3 (November 2012): 297-301, at 299-300; Marloes L.P. Langelaan et al., "Meet the new meat: tissue engineered skeletal muscle,'" Trends In Food Science \& Technology 21:2 (February 2010); 59-66; Kristel J.M. Boonen et al., "Effects of a combined mechanical stimulation protocol: Value for skeletal muscle tissue engineering," Journal of Biomechanics 43:8 (May 28, 2010): 1514-1521. See also H.P. Haagsman, K.J. Hellingwerf, B.A.J. Roelen, Production of animal proteins by cell systems: Desk study on cultured meat ("kweekvlees"), Faculty of Veterinary Medicine, University of Utrecht, October 2009; I. Datair and M. 
Betti, “Possibilities for an in vitro meat production system,"' Innovative Food Science and Emerging Technologies 11:1 (January 2010): 13-22; P.D. Edelman et al., "Commentary: In Vitro-Cultured Meat Production," Tissue Engineering 11:5/6 (May/June 2005): 659-662.

${ }^{5}$ Cor van der Weele and Johannes Tramper, "Cultured meat: every village its own factory?,"' Trends in Biotechnology 32:6 (June 2014): 294-296, concluded that economic feasibility represents the real obstacle to culture meat's acceptance.

${ }^{6}$ Mark J. Post, "Cultured beef: medical technology to produce food,"' Journal of the Science of Food and Agriculture 94:6 (April 2014): 1039-1041, at 1040-1041 and Post, Breewood, van Essen, "Cultured beef." 7 Gabor Forgacs' articles include Karoly Jakab et al., "Tissue engineering by self-assembly and bio-printing of living cells,"'Biofabrication 2(2010): doc: 1088/17585082/2/2/022001; Vladimir Mironov, Glenn Prestwich, Gabor Forgacs, "Bioprinting living structures," Journal of Materials Chemistry 17:20 (May 28, 2007): 2054-2060; Vladimir Mironov, “Organ printing: computer-aided jetbased 3D tissue engineering," Trends in Biotechnology 21:4 
(April 2003): 157-161. See also Gabor Forgacs and Vladimir Mironov, "Tissue and organ printing" in McGraw-Hill Yearbook of Science \& Technology 2006 (McGraw-Hill: New York, 2006), 329-331.

${ }^{8}$ Organovo Holdings, Inc., U.S. Securities and Exchange Commission Form 10-K for the Period Ending March 31, 2014, 2-10. See also Economist, "Printing a bit of me" 410:8877 (March 8, 2014): SS18-SS20; Bruce V. Bigelow, “Using Bioprinting Technology, San Diego's Organovo Makes 3D Tissue, Xconomy, April 23, 2013 <wWw.xconomy.com/sandiego/2013/04/23/using-bioprinting-technology-san-diegosorganovo-makes-3d-tissue>; Bruce V. Bigelow, "San Diego's Organovo Develops Bio-Printer Technology to Engineer New Organs,"' Xconomy, January 8, $2010<W W W . x c o n o m y . c o m / s a n-$ diego/2010/01/08/san-diegos-organovo-develops-bio-printertechnology-to-engineer-new-organs>.

${ }^{9}$ I have drawn on Andras Forgacs, Leather and meat without killing animals, TED Talk, n.d. <wWw.ted.com/talks/andras_forgacs_leather_and_meat_without_ killing_animals/transcript?language=end>; Tom Foster, "The Meat Lab: Can Engineered Beef, Chicken, and Pork Save The World,"' Popular Science 283:5 (November 2013): 56-63, 78, 
Ted Greenwald, "A Cattle Ranch In a Petri Dish," Bloomberg Businessweek 4333 (June 10, 2013): 42-43; Ariel Schwartz, “In Five Years, You May Be Wearing A Lab-Grown Leather Jacket," Fast Company, September 24, 2012 <WWW. fastcoexist.com/1680605/in-five-years-you-may-bewearing-a-lab-grown-leather-jacket>; Michael Keller and Txchnologist, "Tissue-Engineered Leather Could be MassProduced by 2017,"' Scientific American, September 18, 2012 $<$ wW. scientificamerican.com/article/tissue-engineeredleather-could-be-mass-produced-by-2017>. Scientific American reprinted this article from Txchnologist website, Michael Keller, "Laboratory Leather: Company to Mass Produce Tissue-Engineered Animal Hides within Five Year,'" September 18, 2012

<WWW.txchnologist.com/post/31791674302/laboratory-leathercompany-to-mass-produce>.

${ }^{10}$ Greenwald, "Cattle Ranch," 43.

11 Forgacs, "Leather and meat."

12 Andras Forgacs quoted in Keller and Txchnologist, "Tissue-Engineered Leather."

${ }^{13}$ U.S. Food and Drug Administration (FDA), Press Release, "FDA Issues Documents on the Safety of Food from Animal 
Clones,"' January 15, 2008. See also FDA, Animal Cloning, Risk Management Plan for Clones and Their Progeny, January 15, 2008; Center for Veterinary Medicine (CVA), FDA, Department of Health and Human Services (HHS), Animal Cloning: A Risk Assessment, January 8, 2008; HHS, FDA, CVA, Guidance for Industry: Use of Edible Products from Animal Clones or their Progeny for Human Food or Animal Feed, December 28, 2006. However, the FDA views the genetic manipulations applied by scientists to animals as falling within the definition of a new animal drug and thus subject to regulation and approval by the agency. See FDA, Genetically Engineered Animals, General Q\&A, n.d. <WWW.fda.gov/Animal/Veterinary/DevelopmentApprovalProcess/G eneticEngineering/GeneticallyEngineeredAnimals/ucm113605.ht $m>$ and HHS, FDA, CVA, Guidance for Industry: Regulation of Genetically Engineered Animals Containing Heritable Recombinant DNA Constructs: Final Guidance, January 15, 2009, revised May 17, 2011.

${ }^{14} 21$ United States Code Sections 601-624 and 9 Code of Federal Regulations Sections 416.4 and .5. 
15 Small Business Innovation Research/Small Business Technology Transfer (SBIR/STTR), Engineered Comestible Meat: Award Information, 2012/SBIR.

${ }^{16}$ SBIR/STTR, Award List: SBIR Phase I: Tissue Engineered Sustainable Leather, 2013/SBIR/Phase I.

17 Breakout Labs, Press Release, "Thiel Foundation's Breakout Labs Announces Newest Grants at the Intersection of Biology and Advanced Technologies,"' August 15, 2012. See also Keith Wagstaff, "Billionaire Peter Thiel's Latest Investment: 3D-Printed Meat,"' TIME.com, August 16, 2012 <WWw. techland . time.com/2012/08/16/billionaire-peter-thielslatest-investment>.

${ }^{18}$ Singularity University, Press Release, "Singularity University Announces Inaugural Synthetic Biology Accelerator Program,'" May 17, 2012.

19 Modern Meadow, Press Release, "Modern Meadow Raises \$10 Million in Series A Funding,"' June 18, 2014. See also Lora Kolodny and Ned Levin, "Li Ka-shing Invests in Modern Meadow: Where's The Beef?,"' Wall Street Journal, June 20, 2014 <wW.blogs.wsj.com/moneybeat/2014/06/20/li-ka-shinginvests-in-modern-meadow-wheres-the-beef>, and Lora Kolodny, “Modern Meadow Raises \$10M to Grow Leather in 
Labs, Not from Livestock,"' Wall street Journal, June 18, 2014 <wW.blogs.wsj.com/venturecapital/2014/06/18/modernmeadow-raises-10m-to-grow-leather-in-labs-not-fromlivestock>.

20 Jennifer Wang, "The Company Leading the Future of Farming,"' Entrepreneur 41:6 (June 2013): 50-61, at 55. ${ }^{21}$ For contrasting views of cultured meat see Mary Catharine 0'Connor, "Food Fight: Give Synthetic Meat a Chance,"' Modern Farmer.com, September 30, 2014 <WWW. modernfarmer.com/2014/09/give-cells-chance> and Celeste Lecompte, “Food Fight: Don't Count on Synthetic Meat to Save the Plant,"' Modern Farmer, com, September 30, 2014 <WWW. modernfarmer. com/2014/09/wheres-beef>.

22 John McDermott, "A Pork Chop to Change The World (Yes, Really)," Inc., November 1, 2012 <wWW.inc.com/johnmcdermott/big-ideas/modern-meadow-in-vitro-meat .html>. ${ }^{23}$ Brendan Koerner, "Will Lab-Grown Meat Save the Planet? or is it only good for cows and pigs?"' Green Lantern, May 20, $2008<w W w$. slate.com/sec-green-lantern>. For background on the technology of electrical muscle stimulation see Marloes L.P. Langelaan et al., “Advanced maturation by electrical stimulation: Differences in response between $\mathrm{C} 2 \mathrm{C} 12$ and 
primary muscle progenitor cells,"' Journal of Tissue

Engineering and Regenerative Medicine 5:7 (July 2011): 529539. 
III. Replacing Conventional and Substitute Foods

8. All-In-One Liquid Meal Replacement: Rosa Labs

Going beyond salt, cheese, egg, and meat substitutes, some want to reinvent food. They seek to change the world's relationship with food by developing a total food replacement product, something designed and optimized by humans, which would transform the way we live.

A market may exist for all-in-one meal replacements, healthy substitutes that are easy and cheap. Fresh organic food is expensive. Shopping for food and cooking meals from scratch is time consuming.

Through his Soylent product, Robert (Rob) Rhinehart set out to develop and commercialize a convenient, relatively inexpensive, but efficient source of nutrition and energy for every human being. He designed the product for those who do not have the means to eat well, for anyone struggling with food allergies, heartburn, acid reflux, or digestive problems, or having trouble controlling their weight or their bad cholesterol level. In his view, it would also help protect the environment by reducing, if not eliminating, much of the waste and harm resulting from 
agricultural and livestock production as well as foodrelated trash. ${ }^{1}$

Someday, Rhinehart hopes that Soylent could be sold everywhere, even in convenience stores. He wants it to compete against cheap, but unhealthy, snack, junk, and fast foods, linked to obesity, diabetes, and malnutrition, currently found all around us in the United States. This chapter explores his quest to have many people live on Soylent for most of their meals.

Other Liquid Food Replacements Meal replacement products are not new. When a hospital patient is too sick to eat, for decades, he or she received groundup food in feeding tubes. Companies, such as Abbott Nutrition, got into the commercial meal replacement game with Ensure. From the 1960s through the 1990s, the diet crowd turned to liquid meal replacements, which made it easy for them to quantify their calorie consumption and lose weight. It became the era of Unilever's SlimFast. More recently, aspiring bodybuilders drink Muscle Milk, a protein shake to build brawn. ${ }^{2}$ 
In short, there are many meal replacement liquid shakes on the market, serving various needs. However, these replacement products can be more expensive than traditional food and may not provide a nutritious diet. Today, Rosa Labs' Soylent aims to market to those craving a healthy, efficient alternative for most of their meals, not dieters, the elderly, or those wanting to build muscle.

Soylent: Its Origins

In a blog, "How I Stopped Eating Food," "3 Rhinehart described his reasons for and how he created a food substitute that provides, according to him, the body with everything it needs for healthy living. Noting the inefficiencies in the existing food system, he stated, "Food is the fossil fuel of human energy. It is an enormous market full of waste, regulation, and biased allocations with serious geo-political implications. And we're deeply dependent on it. In some countries people are dying of obesity, others of starvation. In my own life I resented the time, money, and effort the purchase, preparation, consumption, and clean-up of food was consuming [some two hours a day]...I don't want to lose 
weight. I want to maintain it and spend less energy getting energy." He continued, "I hypothesized that body doesn't need the food itself, merely the chemicals and elements it contains. So, I resolved to embark on an experiment.... I just want to be in good health and spend as little time and money on food as possible. ${ }^{\prime 4}$ He further noted:

"I don't think we need fruits and veggies, though
-- we need vitamins and minerals. We need carbs,
not bread. Amino acids, not milk. It's still
fine to eat these whenever you want, but not
everyone can afford them or has the desire to eat
them. Food should be optimised and personalised.
If Soylent was as cheap and easy to obtain as a
cup of coffee, I think people would be much
healthier and healthcare costs would be lower." ${ }^{5}$
Seemingly, an impossibly busy man, wanting to live as cheaply as possible and seeing conventional food as an inefficient way to survive, in his words, a "system that's too complex and too expensive and too fragile, ${ }^{\prime \prime}{ }^{6}$ he decided to create a new, nutritionally-complete product from scratch. Pouring over textbooks, open access scientific journals, dietary guidelines, and getting some basic biochemistry lessons from a roommate, with a biology background, Rhinehart, an electrical engineer, came up with 
a liquid meal replacement, which he named Soylent, after the 1973 dystopian science fiction movie, "'Soylent Green."

Striving to save nearly all the time and effort, as well as part of the money, which usually went into shopping and preparing food, and cleaning up, he subsisted on his concoction, first for thirty, then sixty days, ${ }^{7}$ without eating food in a conventional sense. Although he started eating real food thereafter, what he calls "recreational meals, ${ }^{\prime 8}$ Rinehart gets some ninety (92) percent of his meals from Soylent, with only one or two conventional meals weekly .

During his two month experiment phase, Rhinehart replaced food entirely with a liquid shake, thick, doughy, odorless, yellowish-beige in color with all the protein, fat, fiber, carbohydrates, and micronutrients, in various portions humans need, allegedly for a balanced diet, but with one third of the calories. He based his recipe on the daily intake recommendations of the Institute of Medicine. There are no meats, fruits, or vegetables, real or substitutional, or any toxins, carcinogens, hormones, or preservatives. 
Soylent: The Product

Allegedly, Soylent provides all the essential materials we need from food, but not any of the "extra stuff," perhaps enabling the body to operate more efficiently. Filling humans' complete nutritional needs, the product contains a number of ingredients. ${ }^{9}$ Lipids come from canola oil; carbohydrates from maltodextrin (commonly derived from corn) and oat flour; protein from rice. In Soylent 1.2, Rhinehart replaced the Omega-3 fatty acids from fish oil with algae oil, cultivated in large fermentation tanks, thereby making the product suitable for vegans. ${ }^{10}$ However, it contains genetically modified organism ingredients, soy, and gluten. Doses of minerals include iron, potassium, magnesium, calcium, and zinc. ${ }^{11}$ To mask the taste of various minerals and vitamins, it contains a small amount of sucralose. He also added some non-essentials, such as antioxidants and probiotics. The only ingredients recognizable as food are canola oil for fatty acids and table salt for sodium chloride.

Soylent and the Food and Drug Administration 
Unless a dietary supplement introduces a new nutritional ingredient, the U.S. Food and Drug Administration (FDA) need not to give its approval for safety or effectiveness before the product goes on the market. ${ }^{12}$ By using previously available ingredients each of which the FDA recognized as safe and which undergo no chemical changes when blended together with water, Soylent, as a traditional dietary supplement, is considered legal. It is not subject to FDA approval or oversight. Thus, the product avoided the FDA's regulatory grasp and its expensive, burdensome, time-consuming testing process. Furthermore, no disclosures need be made to the FDA or consumers of any information about the safety or the purported benefits of soylent.

Rhinehart's Observations After Existing On Soylent For Thirty Days

In addition to saving him time and money, while yearning for the productivity benefits of being healthy, Rhinehart saw the positive, qualitative results after thirty days of subsisting only on Soylent. He noted:

I feel like a six million dollar man. My physique has noticeably improved, my skin is 
clearer, my teeth whiter, my hair thicker and my dandruff gone.... I have more energy than I know what to do with.

My mental performance is also higher.... My working memory is noticeably better.... My awareness is higher.... My reflexes are improved.... I sleep better, wake up more refreshed and alert and never feel drowsy during the day. ${ }^{13}$

However, these are subjective observations. He also transitioned from a diet often devoid of healthy foods to one rich in vitamins and minerals and began exercising. In addition to finding the taste "very good" and not tiring, ${ }^{14}$ Rhinehart explained his reasoning why many people would in the future relegate themselves to a single food source as follows:

Not having to worry about food is fantastic. No groceries, dishes, deciding what to eat, no endless conversations weighing the relative merits of gluten-free, keto, paleo, or vegan. Power and water bills are lower. I save hours a day and hundreds of dollars a month.... I feel liberated from a crushing amount of repetitive drudgery. Soylent might also be good for people having trouble managing their weight. I find it very easy to lose and gain precise amounts of weight by varying the proportions in my drink. ${ }^{15}$

Rhinehart candidly noted some drawbacks. Although it has a one-year shelf life, Soylent does not keep long after mixing with water. Users must refrigerate the mixture and 
consume it within 48 hours. People who enjoy eating food will not like the idea of a liquid meal replacement.

Three months after his thirty-day blog post, "How I Stopped Eating Food, '" he realized that his mixture had the makings of a for-profit company. Rhinehart and his two roommates put aside their wireless networking tech startup project to make inexpensive cell phone towers and went into the synthetic food business. They organized Rosa Labs, LLC in May 2013.

Financing Rosa Labs

To attract funding for Rosa Labs, Rhinehart and his two co-founders launched a crowdfunding campaign in May 2013 with the goal of raising $\$ 100,000$, which they hoped to raise in one month. When they opened up to donations, they met their financial objective in two hours. The crowdfunding campaign, which ended in May 2014, raised more than \$3 million dollars, indicating an extensive market for backers of fuss-free food.

Even before the end of the crowdfunding campaign, in October 2013, the firm closed on a $\$ 1.5$ million seed funding round. ${ }^{16}$ Investors in this round included 
Andreessen Horowitz and Lerer Ventures. Other backers included Initialized Capital and Hydrazine Capital. Start Fund and $Y$ Combinator, the later entity a seed incubator and accelerator, which provided funds for Rhinehart's abandoned wireless network startup, also own part of Rosa Labs .

The company used the seed round funds to help bring its manufacturing in-house, thereby lowering its costs. Funds also went to product development, including hiring a culinary director to work on the product's taste and mouthfeel. Rhinehart also relocated Rosa Labs to Los Angeles to reduce the previous costs of operating in San Francisco.

In January 2015, Rosa Labs received $\$ 20$ million in a Series A funding round, led by Andreesen Horowitz. ${ }^{17}$ Other participating investors included Lerer ventures.

Rosa Labs Ships Soylent

In May 2014, Rosa Labs shipped the first 30,000 units of commercially-made Soylent to customers across the United 
States. ${ }^{18}$ These shipments went to the firm's initial crowdfunding backers.

The commercial version of soylent comes in a powder form, with a day's supply in a plastic pouch containing 1,530 calories of beige powder. Initially, an oil preparation, 480 calories, came in a separate bottle. Today, Soylent uses a blend of powdered oils, sunflower, flaxseed, and algae, as the source of necessary fats. To prepare a meal, a purchaser scoops the powder into a plastic pitcher, which comes with the powder, adds water, and shakes it up, producing a thick, beige liquid, which is yeastly, grainy, somewhat sweet, even dessert-like. The pitcher stores an entire day's worth of the liquid at once.

\section{Award Received}

In 2015, Forbes magazine selected Rhinehart as one of its 30 under 30 in the food and drink category. ${ }^{19}$

Looking To The Future

It is uncertain at present whether soylent represents the end of conventional or substitute food as we know it. 
The geek dream of a post-food future not only has advantages, but also question marks and negatives.

On the plus side, soylent is much cheaper than other liquid meal replacement products. ${ }^{20}$ At $\$ 85$ (as a one time purchase) for seven bags, with one bag providing more than three meals or $\$ 70$ (as a monthly subscription) for a week's supply, it can also compete pricewise against the ubiquitous snack, junk, and fast foods. Even lower prices exist for two week and one month supplies. It is much healthier than these food sources. It is easy to use, nutrient-rich, and hunger-curbing. With its lack of "real" food sources, except canola oil, salt, oat flour, and rice protein, Soylent should scale well in manufacturing and distribution, unlike fresh fruits and vegetables, which are incompatible with scale. Besides being cheaper, it is customizable for those requiring considerable protein or not needing as many calories. However, mainstream physicians and dietitians remain skeptical about Soylent. We do not know everything that goes into optimally health diet, beyond just surviving. No one understands the long-term implications of switching their diet exclusively or mostly to Soylent. One 
registered dietitian and an assistant professor of medicine warned that a strong possibility exists that a soylent diet could miss something critically important from the essential nutrients in food. Humans may need the substances found in "real" foods, most notably phytochemicals, which come from the plants. These compounds seemingly provide health benefits, but we do not know for certain. Lycopene, which makes tomatoes red, may lower prostate cancer rates. Flavonoid compounds, which make blueberries blue, are linked to lower diabetes rates. Her bottom line: "I would not promote this type of diet to the general public, as there are many ways it can go wrong, especially if consumed long-term. ${ }^{\prime 21}$

In short, it's difficult to itemize a final list of what humans need for health and wellness. For those with pre-existing medical conditions, claiming all the nutrients each human requires is dangerous.

Beyond these health and wellness concerns, among those apathetic toward food, soylent may find a market as a niche product. Those who only see meals in terms of their utility and functionality, who want to optimize their daily routine, allowing more time for them to do what they love, 
perhaps being more productive, may gravitate toward Soylent .

For most of us, however, food is more than utility and functionality. It represents socialization, if not celebration, with family and friends. It is tied to culture and tradition. By sharing a meal we create and maintain relationships. Some obtain their identity through the food they consume. As one journalist concluded, "And like sex, food is fraught with emotional, psychological, social, cultural, gender and religious associations. ${ }^{22}$ The bottom line: Soylent likely will not lead to the end food, whether traditional or substitutional. The product represents a convenient, healthy, relatively affordable alternative. We may see it used in combination with traditional food or animal product substitutes. For this middle way, users can drink it when they want to; they can eat food when they desire both sustenance and pleasure.

${ }^{1}$ Rosa Labs, "About" <wWw. rosalabs.com/about> (December 10, 2014). See also Ron Nixon, "Food Waste Is Becoming Serious Economic and Environmental Issue, Report Says,'" New York Times, February 26, 2015, A16. 
${ }^{2}$ Lizzie Widdicombe, "The End of Food," New Yorker 90:12 (May 12, 2014): 28-35, at 30 .

${ }^{3}$ rob (Rob Rhinehart), "How I Stopped Eating Food," February 13, 2013 <wWw. robrhinehart.com/?p=298> (September 15, 2014). See also Widdicombe, "The End;" Adrian Chen, "Power People: Could it possibly be healthy to eat nothing but a nutrient-laden brown sludge named Soylent? A number of seemingly smart young guys think so," New York, November 4, 2013, 44-46; Economist.com, "Gruel today, gruel tomorrow,'" May 25, 2013 <WWW. economist. com/blogs/babbage/2013/05/nutrition>. ${ }^{4}$ rob, "How I Stopped."

${ }^{5}$ Rob Rhinehart quoted in Monica Heisey, "This Man Thinks He Never Has To Eat Again,"' Vice, March 13, 2013 <wWW.vice.com/en_uk/read-rob-rhinehart-no-longer-requiresfood>.

${ }^{6}$ Rob Rhinehart quoted in Widdicombe, "The End," 28.

${ }^{7}$ Rhinehart summarized his sixty day experiment in rob, "Two Months of Soylent," March 18, 2013 <wWW. robrhinehart.com/?p=474> (December 10, 2014).

${ }^{8}$ Rob Rhinehart, "Soylent Funding Announcement," Soylent Blog, October 23, 2013 
<wWw. blog. soylent . me/post64789154918/soylent - funding announcement> (September 25, 2014).

${ }^{9}$ In the spirit of the open source movement, Rhinehart posted the recipe online. rob, "What's In Soylent," February 14, 2013 <ww. robrhinehart.com/?p=424> (December 9, 2014). For the nutritional facts on Soylent 1.0 see Soylent, "Soylent 1.๑ Final Nutrition," January 27, 2014 <wWw. blog. soylent . me/post/74770956256/soylent-1-0-finalnutrition> (December 9, 2014) and Soylent, "Formula 1.0 Applications Overview'" January 13, 2014 <wWW. blog. soylent.me/post/73232819517/there-is-more-tofood-than-nutrition> (December 9, 2014). For the nutritional aspects of Soylent 1.4 , its latest version, see Soylent, "About Soylent: Nutrition"

<wWw.faq. soylent.me/hc/en-us/articles/200789315-Nutrition> (April 7, 2015), "About Soylent: The Product" $<$ wWw faq. soylent . me/hc/en-us/sections/200307055-About Soylent> (April 7, 2015), "Soylent 1.4 begins shipping today"' <wWW.blog.soylent.me> (April 7, 2015).

${ }^{10}$ Soylent, "Announcing Soylent 1.2," November 10, 2014 <wWw . blog . soylent . me/post/102285900727/announcing-soylent 1-2-development-of-the-soylent> (December 9, 2014). 
${ }^{11}$ On the need to add iron to the mixture, see rob, "How I Stopped."' Among other items, Rhinehart changed the mixture's potassium, magnesium, and calcium composition, rob, "Two Months," and replaced part of the maltodextrin carbohydrates to increase the fiber content, rob, "Soylent Month Three,'" April 25, 2013 <wWw.robrhinehart.com/p=570> (December 10, 2014).

12 The term "dietary supplement" is defined in 21 Code of Federal Regulations $\S 321(\mathrm{ff})$, provided a product is not represented as the sole item of a diet. See generally Food and Drug Administration, "Q\&A on Dietary Supplements," <WWW.fda.gov/Food/DietarySupplements/QADietarySupplements/d efault.htm\#FDA_role>. 13 rob, "How I Stopped."

${ }^{14}$ Other reactions to Soylent vary from the positive, likening it to a vanilla milkshake with a pancake batter texture (Business Insider, "'Soylent Review," July 14, 2014 <WWW. businesssinsider.com/soylent-review-2014-7>) and to negative, for example, comparing the taste to "homemade nontoxic Play-Doh"' (Farhad Manjoo, “The Soylent Revolution Will Not Be Pleasurable,"' New York Times, May 28, 2014, B1) . 
${ }^{15}$ Rob Rhinehart quoted in Heisey, "This Man Thinks." See also Dylan Love, "'Rob Rhinehart: “How I Stopped Eating Food,' Business Insider, March 19, 2013

<WWW. businessinsider.com/rob-rhinehart-food-substitutesoylent-2013-3>

${ }^{16}$ Rhinehart, "Soylent Funding Announcement." See also KimMai Cutler, "Soylent Closes \$1.5M In Seed Funding From Lerer, Andreessen Horowitz,"' TechCrunch, October 21, 2013 <wW. techcrunch.com/2013/10/21/soylent>. Julio Miles, "Soylent Update 5/1," <wWw.discourse.soylent.me/soylentupdate-5-1/12590> (December 9, 2014).

${ }^{17}$ Rob Rhinehart, Blog, "Soylent Raises Money,"' January 14, $2015<w W W$. robrhinehart.com>.

18 Julio Miles, "Soylent Update 5/1,"

<wWW. discourse. soylent . me/soylent-update-5-1/12590> (December 9, 2014).

19 Forbes, "30 Under 30" 195:1 (January 19, 2015): 78-94, at 85 .

${ }^{20}$ Soylent, "'Soylent Website Launch,"' May 5, 2014 <wWw.blog.soylent.me/post/84876359012/soylent-websitelaunch>. 
${ }^{21}$ Diane Stadler quoted in Klint Finley, "Silicon Valley And The Reinvention of Food,"' TechCrunch, May 3, 2013 $<$ wWw. techcrunch. com/2013/05/03/silicon-valley-tries-toreinvent-food-literallys. See also Stella Metsovas, health expert and nutritionist, noting, “I see a real flag for a potential eating disorder." Stella Metsovas quoted in Jennifer Welsh, "Nutritionist Explains Why The 'Stop Eating Food Diet' Is Dangerous and Unhealthy,'" Business Insider, March 19, 2013 <wWw.businessinsider.com/robrhinehart-food-substitute-eating-disorder-2013-3>. But see Dylan Matthews, "Rob Rhinehart has a crazy plan to let you go without food forever. It just might work,"' washington Post blog, March 14, 2013

<wWW . washingtonpost . com/blogs/wonkblog/wp/2013/03/14/robrhinehart-has-a-crazy-plan-to-let-you-go-without-foodforever-it-just-might-work>.

${ }^{22}$ Kate Murphy, "'Rethinking Eating,"' New York Times, August 24, 2014, SR5. See also Dylan Love, "Soylent Is Like A Productivity Cheat Code - And More Observations From Two Weeks On The Meal Replacement Drink,'" Business Insider, July 14, 2014 <wWw. businessinsider.com/soylent-review-20147>; Chris Ziegler, "Soylent survivor: one month living on 
lab-made liquid nourishment,"' The Verge, July 17, 2014

<wWW . theverge . com/2014/7/17/5893221/soylent - survivor - one -

month-living-on-lab-made-liquid-nourishment>; Manjoo, "The Soylent Revolution.'" 
9. Conclusion

The seven for-profit companies profiled in this book are leading the reinvention of food and condiments. Their scientists, entrepreneurs and funders want to spark a revolution that will remake our relationship with our planet and animals. Taking advantage of new technologies and changing tastes, they want to develop food products that will compete against the cheap, but unhealthy, snack, junk, and fast foods, linked to obesity, diabetes, and malnutrition, found all around us.

These firms want us to rethink how we get salt, mayonnaise, animal products, such as cheese, eggs, and meat, and even our food. This reassessment will occur in light of animal welfare ethical quandaries, human health risks, resource scarcities, and environmental concerns.

A blend of approaches to food may evolve, with Rosa Labs' Soylent remaining a niche product. We may see plantbased protein, in the form of cheese, eggs, meat, alongside sustainably-raised chickens and cows and less meatintensive diets. A healthy attitude to food rests on balancing different objectives, not allowing claims of one group, whether animal ethicists or environmental activists, 
to deny the claims of others. Thus, it currently seems unlikely that in coming decades vegetable-generated beef will constitute the only meat many young people will have ever tasted.

In a world of live and let-live, picking corporate winners and also-rans represents a difficult endeavor. If the link between salt and high blood pressure holds, Nu-Tek Food Science may represent one of the firms most likely to succeed.

With respect to the four plant-based firms, Lyrical Foods (cheese) and Hampton Creek (eggs) seem poised to take advantage of their technologies, funding, and consumers search for healthier, more sustainable products. Likewise, Beyond Meat will likely successfully meet the growing demand for healthier, more sustainable chicken strips and beef burgers.

The disruptive efforts of Impossible Foods and possibly Modern Meadow will force some of us to reassess how we get animal protein, particularly beef. In fulfilling the growing demand for healthier, more sustainable beef, these producers of artificial meat, along with Beyond Meat, whether plant-based or cultured, face the 
"yuck" factor. It's a nice idea, but not for me. Theoretically, it would be simpler and cheaper just to stop eating meat (or meat-like products) and become a vegetarian or a vegan, living on vegetables, fruits, nuts, and grains. However, this is not likely for most of us.

Most humans like meat and want to continue eating it. We have a strong tendency to enjoy meat. We crave meat and have evolved to eat it. Thus, it is unlikely whether beef from plants or lab-grown will become a mass substitute to going vegan or vegetarian.

With future technological advancements with respect to synthetic fat, blood vessels, and other vascular structures that give beef its mouthfeel and taste, it seems likely that companies, especially Impossible Foods, will be able to engineer plant-based products that are identical with beef in almost every way. Some day, it will come raw and be sold in the butcher aisle. It will be free of contaminants and include added ingredients, such as Omega3, not naturally found in beef. Although removing the need for animals to die in production process, it is unclear whether carnivores will be irked by products, such as artificial beef, pretending to be "real" meat. In short, 
Impossible Foods, and even Beyond Meat, face a marketing challenge in wooing beef lovers.

Some, especially vegans and vegetarians, among others, deeply distrust processed foods. Although traditional foods, such as cheese, yogurt, and beer, are engineered, the beef offered by Impossible Foods, Beyond Meat, and especially by Modern Meadow, with its in vitro meat regarded somehow as "unnatural," fly in the face of current food trends favoring whole, fresh, local, unprocessed foods, mostly plants and vegetables. By preparing a meal consisting of "real" food, more proactive wellness consumers are trying to eat what nature gives them, avoiding processed foods, at least to some degree. The movement to eating more organic foods and fewer animal products typically shuns processed foods. Although fresh, organic produce is expensive for consumers, it is low-tech. These protein substitutes, especially meat, constitute processed foods. Beef and possibly chicken may be viewed, at least by some, as another artificial product offered by the broken, commercial food industry. Those wary of processed foods may be suspicious of all the ingredients, 
even if all natural, animal-free, and without costs to the environment and human health.

If beef substitutes become cost effective and thus commercially viable, it is uncertain whether Beyond Meat and Impossible Foods will reach the scale and market values of Internet firms. To gain greater acceptance, as noted, these companies will likely switch from frozen to raw meat. However, food represents a difficult nut to crack if it is perishable. Thus, it is harder to create scalable, high margin, perishable food businesses.

However, even if a small percentage of U.S. customers switch from real chicken or beef to plant-based meat, the market would be huge. Validating venture capitalists' funding, these substitute products would then represent a transformative, disruptive technology. As traditional food companies lose market share to upstarts, Unilever's withdrawn lawsuit against Hampton Creek's Just Mayo likely represents the opening salvo in the coming struggle for profits.

As consumers, scientists, entrepreneurs, and funders face the problem of the impact of foods on human health and the environment, from a policy perspective, regulators most 
strive to keep pace with emerging trends and developments. The U.S. Food and Drug Administration must review its regulations, beginning with the definition of mayonnaise, in light of plant-based animal products. The federal regulators must also assess their future response to the commercialization of cultured meat. Apart from regulation, technical and cost factors weigh against Modern Meadow's successful development of beef, but not leather. Beyond any specific product, such as lab-grown meat, the federal regulatory process must evolve to deal with how people are starting to eat, now and in the future.

Today, the federal food regulatory process represents a complex web. Fifteen federal regulatory agencies have a role in making certain that the food Americans eat is safe. Proposing the creation of a new federal unit, the Food Safety Administration to be housed in the U.S. Department of Health and Human Services (HHS), in 2015 the Obama administration sought to untangle the current bureaucratic and fragmented web that has defied streamlining for decades. ${ }^{1}$ According to the Government Accountability Office, the current system is "high-risk" because of "inconsistent oversight, ineffective coordination, and 
inefficient use of resources. ${ }^{\prime \prime 2}$ Furthermore, as a result of foodborne illnesses, each year some 48 million Americans get sick, 128,000 are hospitalized with food-related illnesses, and 4,000 die from food-related diseases. ${ }^{3}$

For proponents of consolidation, a single food entity, whether housed in the HHS or a stand-alone agency, ${ }^{4}$ would ensure that one regulatory body is accountable for the entire spectrum of food safety issues, including applied research, prevention, inspection, labeling, enforcement, and outbreak response. The single entity would thus improve governmental efficiency. However, entrenched bureaucracies are difficult to meld. The Department of Agriculture and the Food and Drug Administration, the two key food safety agencies, have different mandates, operate different types of inspection programs, and require different levels of education and training for inspectors. Also it is uncertain whether a single agency would unnecessarily compromise food safety efforts by lowering the standards for meat and poultry inspection.

I want to conclude on an optimistic, but speculative, note. The future is wide open. Beyond chickens and cows, the for-profit companies profiled in this book and other 
emerging startups can go beyond imitating known animal products, including cheese, eggs, and meat. They may create entirely novel food products, raising opportunities for scientists, entrepreneurs, and funders, but new regulatory challenges.

${ }^{1}$ Office of Management and Budget, Fiscal Year 2016 Budget of The U.S. Government, 65, 81-82. See also Ron Nixon, "Obama Proposes Single Overseer for Food Safety," New York Times, February 21, 2015, A12.

${ }^{2}$ United States Government Accountability Office, Report to Congressional Committees, High-Risk Series: An Update, February 2015, GA0-15-290, 262.

3 Ibid.

${ }^{4}$ Proposed Safe Food Act of $2015,114^{\text {th }}$ Congress, $1^{\text {st }}$ Session. See also Renée Johnson, Food Safety Issues for the $114^{\text {th }}$ Congress, Congressional Research Service, February 13，2015，R42885， 26-27. 
